\title{
Estimating dynamic changes of tissue attenuation coefficient during high-intensity focused ultrasound treatment
}

\author{
Siavash Rahimian and Jahan Tavakkoli*
}

\begin{abstract}
Background: This study investigated the dynamic changes of tissue attenuation coefficients before, during, and after high-intensity focused ultrasound (HIFU) treatment at different total acoustic powers (TAP) in ex vivo porcine muscle tissue. It further assessed the reliability of employing changes in tissue attenuation coefficient parameters as potential indicators of tissue thermal damage.

Methods: Two-dimensional pulse-echo radio frequency (RF) data were acquired before, during, and after HIFU exposure to estimate changes in least squares attenuation coefficient slope $(\Delta \beta)$ and attenuation coefficient intercept $\left(\Delta a_{0}\right)$. Using the acquired RF data, $\Delta \beta$ and $\Delta a_{0}$ images, along with conventional B-mode ultrasound images, were constructed. The dynamic changes of $\Delta \beta$ and $\Delta a_{0}$, averaged in the region of interest, were correlated with B-mode images obtained during the HIFU treatment process.

Results: At a HIFU exposure duration of $40 \mathrm{~s}$ and various HIFU intensities $\left(737-1,068 \mathrm{~W} / \mathrm{cm}^{2}\right), \Delta \beta$ and $\Delta a_{0}$ increased rapidly to values in the ranges $1.5-2.5 \mathrm{~dB} /(\mathrm{MHz} . \mathrm{cm})$ and $4-5 \mathrm{~dB} / \mathrm{cm}$, respectively. This rapid increase was accompanied with the appearance of bubble clouds in the B-mode images. Bubble activities appeared as strong hyperechoic regions in the B-mode images and caused fluctuations in the estimated $\Delta \beta$ and $\Delta a_{0}$ values. After the treatment, $\Delta \beta$ and $\Delta a_{0}$ values gradually decreased, accompanied by fade-out of hyperechoic spots in the B-mode images. At 10 min after the treatment, they reached values in ranges $0.75-1 \mathrm{~dB} /(\mathrm{MHz} . \mathrm{cm})$ and $1-1.5 \mathrm{~dB} / \mathrm{cm}$, respectively, and remained stable within those ranges. At a long HIFU exposure duration of around $10 \mathrm{~min}$ and low HIFU intensity $\left(117 \mathrm{~W} / \mathrm{cm}^{2}\right), \Delta \beta$ and $\Delta a_{0}$ gradually increased to values of $2.2 \mathrm{~dB} /(\mathrm{MHz} . \mathrm{cm})$ and $2.2 \mathrm{~dB} / \mathrm{cm}$, respectively. This increase was not accompanied with the appearance of bubble clouds in the B-mode images. After HIFU treatment, $\Delta \beta$ and $\Delta a_{0}$ gradually decreased to values of $1.8 \mathrm{~dB} /(\mathrm{MHz} . \mathrm{cm})$ and $1.5 \mathrm{~dB} / \mathrm{cm}$, respectively, and remained stable at those values.
\end{abstract}

Conclusions: $\Delta \beta$ and $\Delta a_{0}$ estimations were both potentially reliable indicators of tissue thermal damage. In addition, $\Delta \beta$ and $\Delta a_{0}$ images both had significantly higher contrast-to-speckle ratios compared to the conventional B-mode images and outperformed the B-mode images in detecting HIFU thermal lesions at all investigated TAPs and exposure durations.

Keywords: HIFU, Thermal lesion, Treatment monitoring, Tissue attenuation coefficients, Contrast-to-speckle ratio

\footnotetext{
* Correspondence: jtavakkoli@ryerson.ca

Department of Physics, Ryerson University, 350 Victoria Street, Toronto,

Ontario M5B 2K3, Canada
}

\section{Biomed Central}

(c) 2013 Rahimian and Tavakkoli; licensee BioMed Central Ltd. This is an Open Access article distributed under the terms of the Creative Commons Attribution License (http://creativecommons.org/licenses/by/2.0), which permits unrestricted use, distribution, and reproduction in any medium, provided the original work is properly cited. 


\section{Background}

High-intensity focused ultrasound (HIFU) is a non- or minimally invasive modality for conducting hightemperature thermal therapy. HIFU has the capability to induce biological effects deep into the body by delivering acoustic energy at a distance from the source, and to generate a millimeter-size focal region [1]. The HIFU beam induces biological effects in the focal region via thermal and mechanical mechanisms.

This study is focused on tissue damage caused predominantly by thermal mechanisms of HIFU. In the thermal mechanism, the acoustic wave energy is converted to heat through a variety of effects such as viscous shearing effects and relaxation processes [2]. The typical HIFU beam can generate intensities in the range of a few hundred to a few thousand watts per square centimeter at the focal point [1]. The combination of tight focusing and high intensities generated by the HIFU beam results in the generation of high temperatures (in excess of $60^{\circ} \mathrm{C}$ in the tissue) at the focal spot, resulting in instantaneous cell death primarily through coagulative necrosis, without heating the surrounding tissues $[3,4]$.

Monitoring HIFU therapies ensures that the target volume is completely treated (thermally damaged). In addition, it ensures the safety of sensitive structures near or outside the target volume. The monitoring and assessment methods employed for HIFU treatments are divided into two major categories. In the first category, the thermal damage and structural changes in tissue are detected and monitored. In the second category, also known as thermometry, the tissue temperature at the target volume is monitored, providing feedback to the interventionist or an automated system.

$\mathrm{X}$-ray imaging, magnetic resonance imaging (MRI), and ultrasound imaging have all been used as noninvasive methods for monitoring and assessment of tissue thermal damage in HIFU surgeries. X-ray was the earliest imaging modality used for guidance and monitoring of HIFU [5]. However, it has the usual problem of exposing both the patient and the interventionist to high doses of ionizing radiation during rather long HIFU treatment procedures. Significant advances have so far been made in the application of MRI for guidance in thermal therapies and more specifically HIFU therapy [6]. However, low image acquisition speeds (low temporal resolution), high costs, requirement for the use of MRI-compatible parts, and fitting everything within the confined space of the MRI chamber have restricted the use of MRI for HIFU treatment monitoring and control.

Ultrasound imaging is an attractive and promising modality for real-time monitoring of HIFU treatments. The past and current states of ultrasound-guided HIFU were recently reviewed by Tavakkoli and Sanghvi [7].
One of the most straightforward methods of HIFU lesion detection and visualization is ultrasound B-mode imaging $[8,9]$. In the first studies in which ultrasound was used to monitor high-temperature thermal therapies, it was observed that due to the formation and presence of strongly scattering gas bubbles during HIFU treatment, a region with very high echogenicity usually appeared at or in the vicinity of the focal region. The echogenicity of the hyperechoic regions was quantified for the purpose of evaluating tissue thermal damage after each HIFU exposure [10]. However, it has been shown that the hyperechoic region is consistently smaller than the actual coagulated region in the tissue, and it has a different shape. Therefore, it is not an accurate indicator of tissue thermal damage. The use of B-mode imaging to monitor HIFU relies on the presence of cavitation and microbubble activities [11]. Cavitation and microbubble activities strongly correlate with unpredictable HIFU lesions [12], and in applications where avoidance of microbubble activities is desirable, relying on B-mode imaging will be problematic.

Tissue elastic modulus (stiffness) is another physical parameter that can be exploited for HIFU lesion detection. HIFU lesions can be significantly stiffer than normal tissue [13]. Therefore, changes in tissue elastic modulus can be used to estimate the size and location of HIFU lesions. A number of elastographic measurement techniques have been proven feasible for the detection and characterization of HIFU-induced lesions [14-16]. However, with the exception of acoustic radiation force imaging technique [16], they all require extra instruments to apply an external stress in order to create the desired strain in the tissue. In addition, a uniform application of the stress to deepseated tissues and regions that are generally not accessible, along with contamination of elasticity maps by motion artifact distortions [17], have imposed further limitations on elastographic techniques.

Tissue temperature can be noninvasively estimated by detecting and measuring changes in speed of sound as a function of temperature [18-21]. However, factors such as nonlinearity [22,23], thermal expansion, the effect of different intensity levels, accuracy of in vivo measurements [24], lack of sufficient data tabulating the relationship between temperature and speed of sound for different types of tissue, and finally inter-patient variability [25] have so far imposed serious limitations on noninvasive temperature measurement using ultrasound.

Studies conducted on changes in ultrasound tissue attenuation coefficient as a function of temperature or thermal dose [24,26-28] have shown that there is a significant increase in tissue attenuation coefficient as the temperature of tissue rises and ultimately as the tissue coagulates. Frequency-dependent ultrasound attenuation and its changes as a function of temperature or thermal dose are potentially valuable methods for differentiating 
normal and thermally coagulated tissue. Therefore, measurement of change in ultrasound attenuation can be exploited to monitor HIFU therapies. Ophir et al. extensively discussed various methods of attenuation estimation using radio frequency (RF) backscattered ultrasound signals [29]. Using attenuation mapping, it was shown that a thermally coagulated region (HIFU-induced lesion) of an ex vivo liver tissue can be effectively detected [30]. Bevan and Sherar developed one algorithm based on detecting changes in the slope of the logarithm of the envelope of the RF backscattered ultrasound signals [31] and another one based on the shift in the center frequency of such signals [32] to generate attenuation maps for monitoring of hightemperature thermal therapies. Seip et al. conducted a comparison of a few detection algorithms, including attenuation change, for real-time monitoring and control of HIFU lesions in in vivo canine prostates using RF backscattered ultrasound signals [33]. Most recently Zhang et al. studied the feasibility of using attenuation estimation using RF backscattered ultrasound signals, along with other RFbased methods for the monitoring of HIFU in transparent tissue-mimicking phantoms and in ex vivo bovine liver [34].

Our study was designed to investigate the possibility that changes in the tissue attenuation of HIFU lesions can be estimated with respect to initial attenuation of normal tissue, using the acquired backscattered ultrasound RF data. The aim was to (1) design and develop a system (both hardware and software) capable of acquiring backscattered ultrasound RF data before, during, and after any given HIFU exposure; and (2) design and implement suitable signal processing algorithms capable of quantitatively characterizing changes in attenuation of tissue in locations where HIFU lesions are created, in real-time, using the acquired backscattered ultrasound RF data. Two frequency domain algorithms were developed, and the transient characteristics of tissue attenuation coefficient parameters before, during, and after HIFU exposure at different total acoustic power (TAP) values in ex vivo porcine muscle tissues were investigated. In addition, tissue attenuation maps were generated and were further correlated with Bmode images. Finally, the imaging performances of the attenuation maps in detecting HIFU lesions were compared with each other and with conventional B-mode images.

\section{Materials and methods}

\section{Experimental setup}

Figure 1 illustrates the schematic diagram of the experimental setup. The HIFU transducer was installed inside a water tank filled with degassed and deionized water at room temperature. The tissue sample placed on the tissue holder would then be submerged in the tank at the focal region such that it would cover the entire focal area. The imaging probe was installed confocally through a hole at the center of the HIFU transducer (Figure 2) to ensure that it was always scanning the focal region of the HIFU transducer in the imaging plane.

The thermal effects of the HIFU treatments during the slow HIFU were measured in the tissue samples by monitoring the temperature change during lesion formation using two K-type calibrated thermocouples (made in-house). The calibrated thermocouples were built using 76.2- $\mu \mathrm{m}$ chromel and alumel wires (California Fine Wire, Grover Beach, CA, USA) and then placed inside 22 -gauge needles. The thermocouples were implanted at the focal region and the post-focal region of the HIFU beam. The temperature data that were obtained from the focal region and post-focal regions provided information with regard to the extent of thermal damage within the tissue sample. In addition, they were utilized to control the experiment and to ensure that the HIFU beam was only targeting the focal region without causing any thermal damage to the post-focal region.

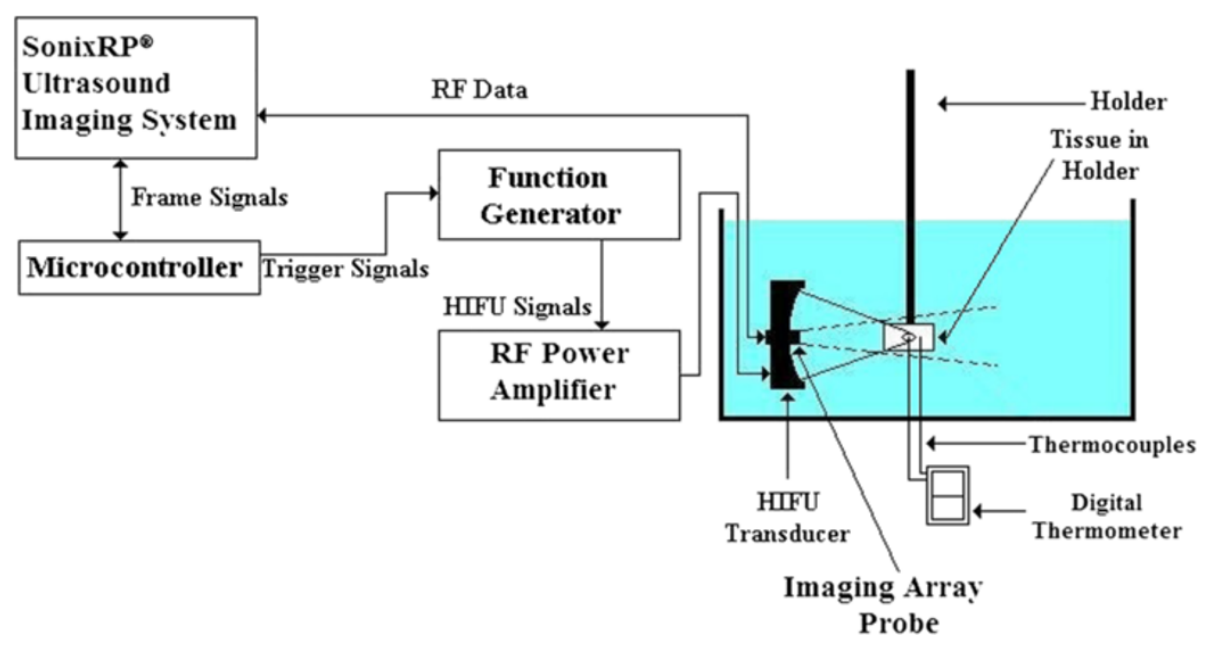

Figure 1 The image-guided HIFU experimental setup. 


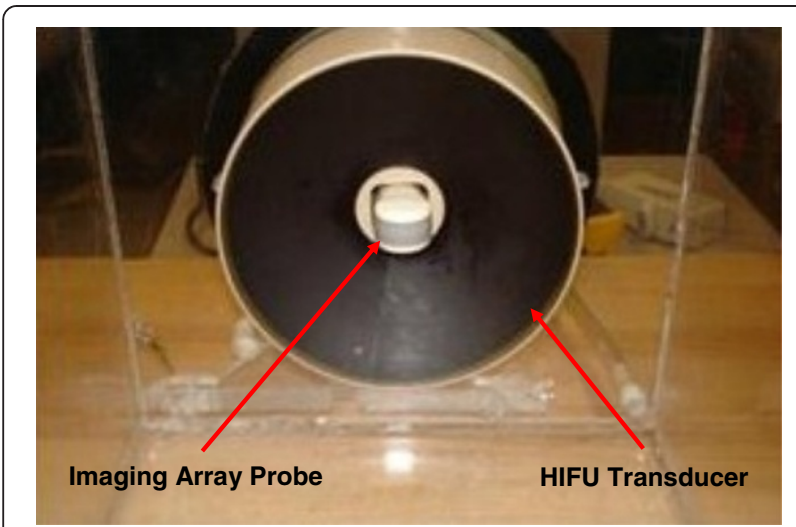

Figure 2 The HIFU transducer and the imaging probe in a confocal arrangement.

\section{Porcine muscles}

The experiments were conducted on freshly excised ex vivo porcine muscle tissues purchased from a local butcher shop within $6 \mathrm{~h}$ of butchering. The muscle specimens used in the slow HIFU experiments were cut and trimmed to a size of around $100 \mathrm{~mm} \times 120 \mathrm{~mm} \times 100$ $\mathrm{mm}$ and immersed in $0.9 \%$ degassed deionized saline solution at $5^{\circ} \mathrm{C}$. All experiments were performed within $12 \mathrm{~h}$ of purchasing the tissue. Before every experiment, first, all the samples were examined using the conventional Bmode ultrasound images to avoid large layers of fat or cavities in the HIFU acoustic path as this might affect the delivery of HIFU energy to the focal region. In addition, the tissue samples were allowed to reach room temperature while being submerged in the saline solution. Before sonication, the tissue samples were degassed in a desiccator connected to a vacuum pump for $30 \mathrm{~min}$ at an absolute pressure of $4 \mathrm{kPa}$. This procedure has been utilized in other similar studies [34] and has been proven successful in removing air pockets from the tissue. When moving the tissue samples from the desiccator to the tissue holder in the water tank, they were kept submerged in the degassed deionized saline in order to minimize the potential of cavitation generation during HIFU exposure. After HIFU treatment, the samples were sliced along the RF data acquisition plane through the center of the lesion for photo capture and gross pathology examinations.

The muscle specimens used in the 40-s duration HIFU experiments were cut and trimmed to a size of around $20 \mathrm{~mm} \times 80 \mathrm{~mm} \times 100 \mathrm{~mm}$ and were prepared for sonication using the same procedure as above except they did not go through the vacuum pumping step. Similarly, after HIFU treatment, the samples were sliced along the RF data acquisition plane through the center of the lesion for photo capture and gross pathology examination.

\section{HIFU system}

The RF signal driving the HIFU transducer was generated by an arbitrary function generator (Model AFG3010; Tektronix, Beaverton, OR, USA). The RF signal was amplified by a class-A broadband RF power amplifier (Model A150; E\&I, Rochester, NY, USA), with frequency range of $300 \mathrm{kHz}-35 \mathrm{MHz}$, nominal gain of $53 \mathrm{~dB}$, and class-A nominal linear electric output power of $150 \mathrm{~W}$. The output signal was transferred to the HIFU transducer through a matching network to maximize the transmitted power. A single-element piezo-composite HIFU transducer (Model 6699A101; Imasonic S. A., Voray sur l'Ognon, France) with a resonant frequency of $1 \mathrm{MHz}$ was used throughout this study. The transducer had a $125-\mathrm{mm}$ diameter aperture and a 100-mm geometric focal length. The HIFU transducer output signal was characterized by a calibrated needle hydrophone with an active element diameter of $400 \mu \mathrm{m}$ (Model HNA-0400; ONDA Corporation, Sunnyvale, CA, USA). In addition to hydrophone measurements, the acoustic field profile of the HIFU transducer was characterized using computer simulations. The computer simulations were conducted using a linear ultrasound simulation software (Linear Acoustic and Temperature

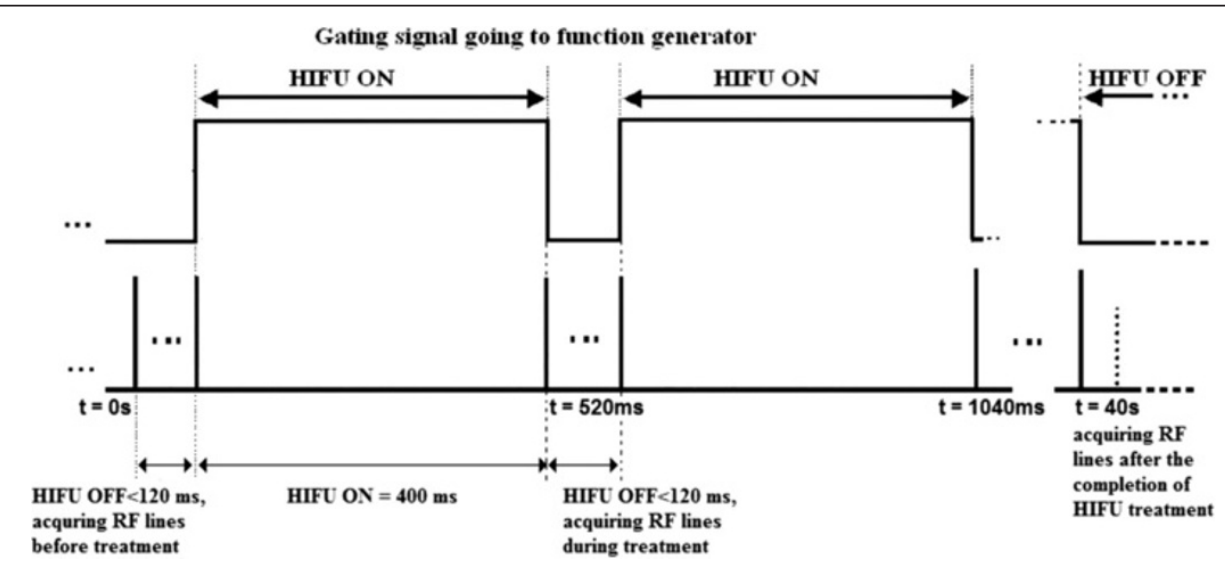

Figure 3 Timing diagram of HIFU exposure and data acquisition. 
Simulation), developed by our research group [35]. The efficiency of the HIFU transducer was defined as the ratio of the converted acoustic power to the transmitted electric power. The transmitted electric power was measured using an electrical power meter (Bird Power Meter 4021; Bird Technologies Group, Cleveland, OH, USA). The acoustic power was measured by a calibrated radiation force balance unit (Model RFB-2000; ONDA Corporation). For the HIFU transducer, the free-field (in water) spatially averaged intensity, $I_{\mathrm{SA}}$, was estimated using the following equation [36]:

$$
I_{\mathrm{SA}}=0.867 \frac{P}{D^{2}}
$$

where $P$ was the TAP measured using the calibrated acoustic power meter at the surface of the transducer, and $D$ is the focal beam width at full width at half maximum (FWHM) measured using the calibrated hydrophone.

\section{Ultrasound imaging system}

An ultrasound imaging system (SonixRP ${ }^{\circledR}$ scanner, Ultrasonix Inc., Richmond, Canada) and an endocavity array probe (EC9-5/10, Ultrasonix Inc.) with 128 elements, center frequency of $7 \mathrm{MHz}$, and bandwidth of $3 \mathrm{MHz}$ were used to acquire backscattered ultrasound RF data. To avoid any interference while acquiring RF backscattered signals during HIFU exposure, the ultrasound imaging system and the function generator were synchronized using a microcontroller (Model M68HC11; Motorola, Inc., Schaumburg, IL, USA).

\section{RF data acquisition}

Backscattered RF data were acquired before, during, and after each HIFU exposure to estimate the initial, transient, and final acoustic properties of tissue. During HIFU treatment, the RF data frames were obtained by briefly turning off the HIFU transducer in order to avoid acoustic and electrical interferences caused by the HIFU transducer.

For the shorter-duration HIFU exposures (40 s), the duration of interruption was $120 \mathrm{~ms}$ (off-time) for every HIFU on-time, allowing the capture of two RF data frames, and the HIFU on-time was $400 \mathrm{~ms}$, resulting in a duty cycle of $77 \%$. The total HIFU treatment time was $40 \mathrm{~s}$ for TAP levels of 34, 37, 39, 44, and $49 \mathrm{~W}$. A total of four lesions were created at every TAP value. RF data were acquired 10 min after the completion of HIFU treatment, and in one case, RF data were acquired $13 \mathrm{~h}$ after the completion of HIFU treatment as well. Figure 3 illustrates the timing diagram of HIFU exposure and RF data acquisition.

During the slow HIFU experiment, the tissue sample was treated with HIFU exposure until the temperature at the focal region, measured by the thermocouple, rose to levels above $60^{\circ} \mathrm{C}$. Consequently, the total HIFU treatment time was 9 min and $39 \mathrm{~s}$ for TAP of $5 \mathrm{~W}$. RF data were continuously acquired for $9 \mathrm{~min}$ after the completion of HIFU treatment (18 min and $39 \mathrm{~s}$ in total).

\section{RF data processing}

In this study, a simplifying assumption was made that the frequency-dependent attenuation coefficient of soft tissue, $\alpha(f)$, increases linearly with frequency $[29,34]$ :

$$
\alpha(f)=\alpha_{0}+\beta\left(f-f_{c}\right)
$$

where $\alpha_{0}$ was the attenuation coefficient $(\mathrm{dB} / \mathrm{cm})$ at the center frequency $\left(f_{\mathrm{c}}\right)$ of the transmitted pulse, and $\beta$ was the least squares attenuation slope (dB/MHz.cm). Parameters $\alpha_{0}$ and $\beta$ are usually referred to as attenuation intercept and attenuation slope, respectively [26].

In the time domain, for an initial pulse $p_{0}(t)$, the pulse $p$ $(t, z)$ propagating in a medium at time $t$ and a distance $z$ can be described by using a convolution operator as [37]

$$
p(t, z)=p_{0}(t) * \operatorname{MIRF}(t, z)
$$

where MIRF is the material impulse response function. Taking the Fourier transfer of both sides results in the following equation in frequency domain:

$$
P(f, z)=P_{0}(f) \operatorname{MTF}(f, z)
$$

where MTF is the material transfer function in the frequency domain, described by [37],

$$
\operatorname{MTF}(f, z)=\exp \left[\gamma_{\mathrm{T}}(f) z\right]
$$

where

$$
\gamma_{\mathrm{T}}(f)=-\alpha_{\mathrm{a}}(f)-i \delta(f)
$$

where $\alpha_{\mathrm{a}}$ is the frequency-dependent absorption loss and

$$
\delta(f)=k_{0}(f)+\delta_{\mathrm{E}}(f)
$$

where $k_{0}$ is the baseline wave number equal to $\frac{\omega}{c_{0}}, c_{0}$ is the sound speed at the center frequency of the spectrum of the pulse, and $\delta_{\mathrm{E}}(f)$ is an excess dispersion term required by causality [37]. 
Table 1 Total acoustic powers and $I_{\text {SA }}$ calculated at corresponding input electric power levels

\begin{tabular}{ccc}
\hline Input electric power $(W)$ & Total acoustic power $(W)$ & $\boldsymbol{I}_{\mathbf{S A}}\left(\mathbf{W} / \mathbf{c m}^{\mathbf{2}}\right)$ \\
\hline 11 & 5 & 117 \\
70 & 34 & 737 \\
75 & 37 & 801 \\
80 & 39 & 845 \\
90 & 44 & 961 \\
100 & 49 & 1,068 \\
\hline
\end{tabular}

For the general case of a given pulse $P_{0}(f)$ propagating in a given material over the paths $z_{1}$ and $z_{2}$

$$
\operatorname{MTF}\left(f, z_{1}+z_{2}\right)=\exp \left[\gamma_{\mathrm{T}}(f) z_{1}\right] \times \exp \left[\gamma_{\mathrm{T}}(f) z_{2}\right],
$$

SO

$$
\operatorname{MTF}\left(f, z_{1}+z_{2}\right)=\exp \left[\gamma_{\mathrm{T}}(\mathrm{f})\left(z_{1}+z_{2}\right)\right] .
$$

In the specific case of pulse-echo imaging,

$$
z_{1}=z_{2}=z
$$

Therefore,

$$
\operatorname{MTF}(f, 2 z)=\exp \left[2 \cdot \gamma_{\mathrm{T}}(f) \cdot z\right] .
$$

The MTF defined in Equation 11 does not take into account the effect of the frequency-dependent scattering $\left(\alpha_{\mathrm{s}}\right)$. To compensate for this deficiency, the scattering properties of soft biological tissue were assumed to remain constant before, during, and after the HIFU exposure. The frequency-dependent attenuation coefficient is described as a linear combination of the frequency-dependent

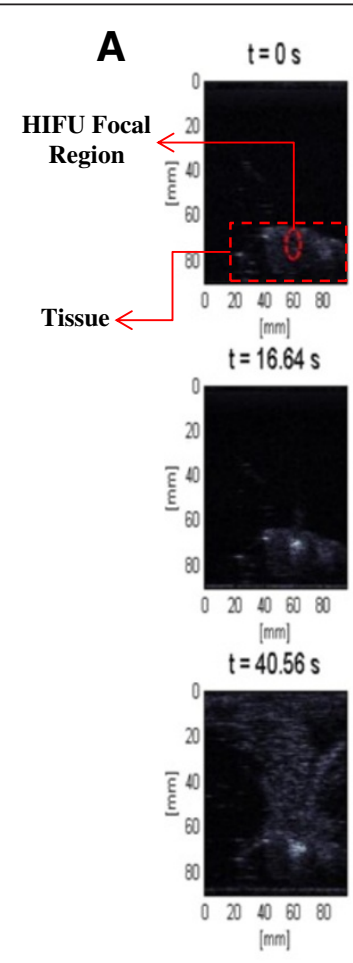

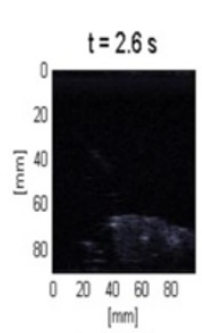

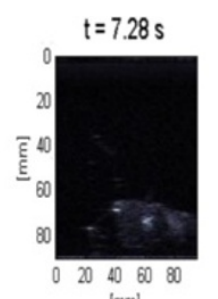

[mm]

$t=26.0 \mathrm{~s}$
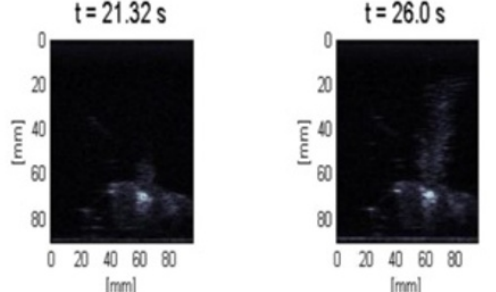

[mm]

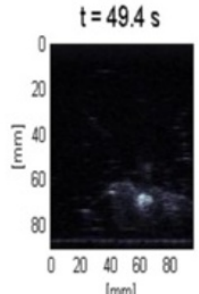

[mm] $t=10 \mathrm{~min}$

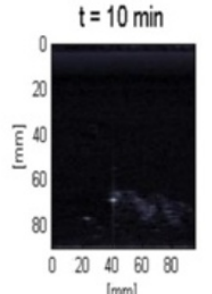

[mm]

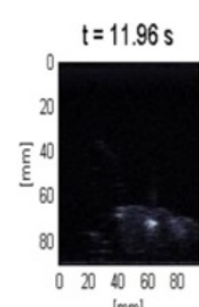

$[\mathrm{mm}]$

$t=30.68 \mathrm{~s}$

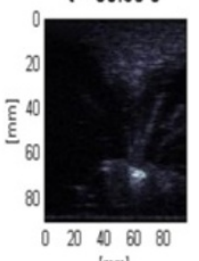

$[\mathrm{mm}]$

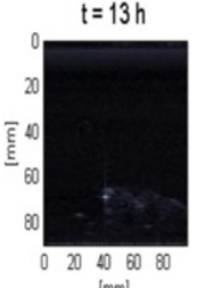

$[\mathrm{mm}]$

B

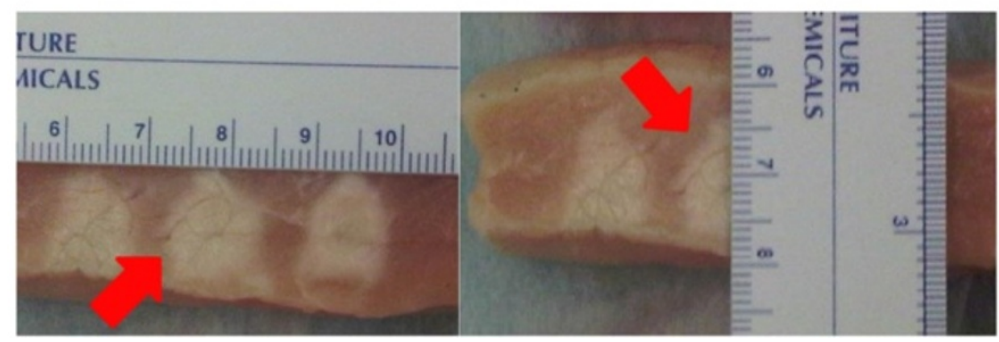

Figure 4 Lesion growth in ex vivo porcine muscle tissue in conventional B-mode images. (A) The duty cycle was 77\%, resulting in TAP of $49 \mathrm{~W}$ and average focal intensity of $1,068 \mathrm{~W} / \mathrm{cm}^{2}$ at the HIFU treatment site, for a total HIFU treatment time of $40 \mathrm{~s}$. (B) Axial section of the lesion induced. 

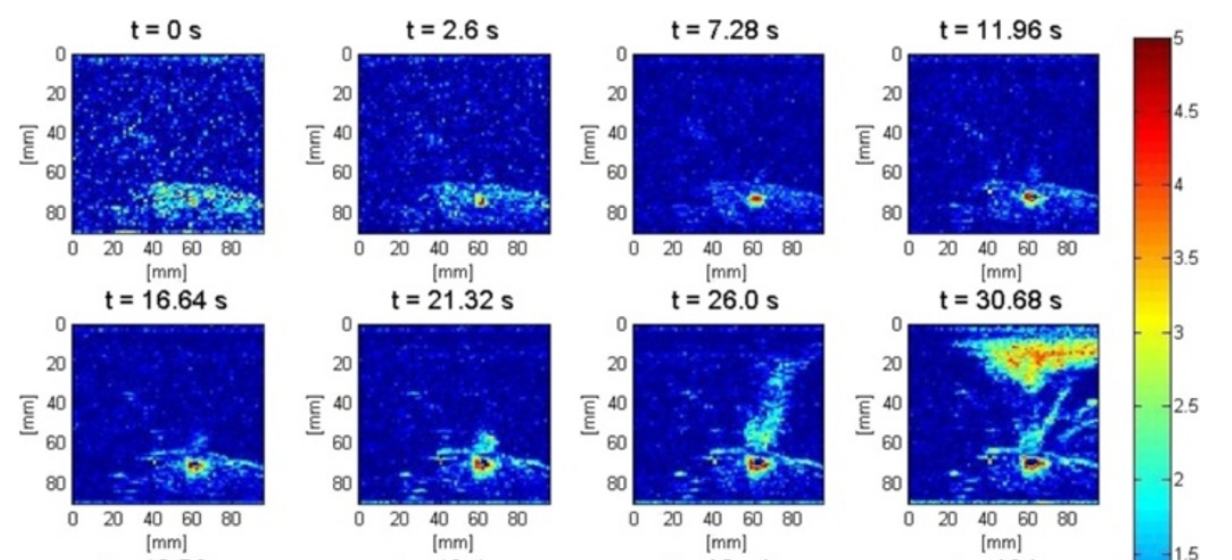

$t=40.56 s$
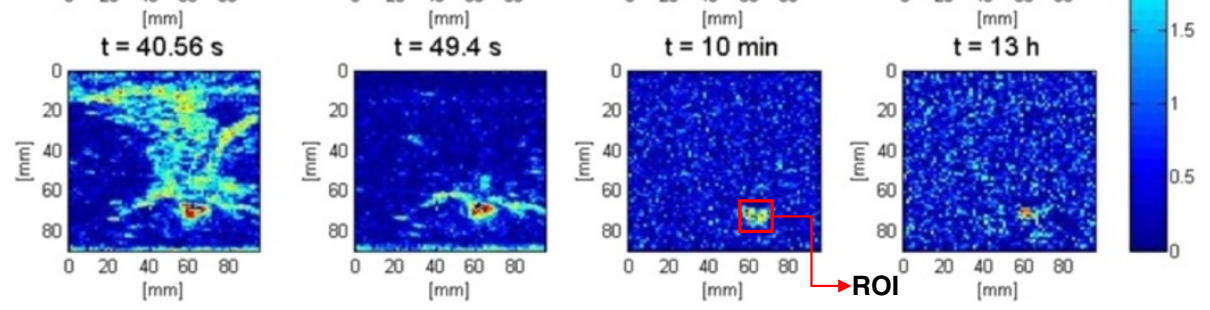

Figure $\mathbf{5}$ Lesion growth in ex vivo porcine muscle tissue in $\Delta \boldsymbol{\beta}$ images. The duty cycle was $77 \%$, resulting in TAP of $49 \mathrm{~W}$ and average focal intensity of $1,068 \mathrm{~W} / \mathrm{cm}^{2}$ at the HIFU treatment site, for a total HIFU treatment time of $40 \mathrm{~s}$.

scattering coefficient and frequency-dependent absorption coefficient as [38]

$$
\alpha(f)=\alpha_{\mathrm{s}}(f)+\alpha_{\mathrm{a}}(f) .
$$

Assuming that $\alpha_{\mathrm{s}}(f)$ remains constant,

$$
\alpha(f)=C+\alpha_{\mathrm{a}}(f),
$$

and by estimating changes in $\alpha_{\mathrm{a}}(f)$, changes in $\alpha(f)$ can be estimated,

$$
\begin{aligned}
& \alpha_{\text {initial }}(f)=C+\alpha_{\text {a_initial }}(f) \\
& \alpha_{\text {final }}(f)=C+\alpha_{\text {a_final }}(f) \\
& \Delta \alpha(f)=\alpha_{\text {final }}(f)-\alpha_{\text {initial }}(f)=\Delta \alpha_{\mathrm{a}}(f) .
\end{aligned}
$$

Given the negligible contribution of velocity dispersion within the narrow bandwidths used in this study (approximately $3 \mathrm{MHz}$ ), the $\delta(f)$ term of $\gamma_{\mathrm{T}}(f)$ was neglected by discarding the imaginary component of $\gamma_{\mathrm{T}}(f)$.

The attenuation slope algorithm was implemented to estimate $\Delta \beta$ by estimating the least squares slope of the line fitted to $\Delta \alpha(f)$. Changes in the least squares slope of the line fitted to $\Delta \alpha(f)$ were constantly estimated throughout the entire treatment cycle with respect to a reference frame obtained right before the HIFU exposure, at $t_{0}(t=0 \mathrm{~s})$. The algorithm would generate a set of two-dimensional matrices, each representing a map of $\Delta \beta$ values (as a function of time $t$, depth $z$, and line number), with respect to the reference frame. The following is a mathematical description of the steps implemented in order to estimate $\Delta \beta$ for one window of signal with respect to a reference window, at location $z$, in the frequency domain [37].

$$
P(f, z)_{\text {signal }}=P_{0}(f) \operatorname{MTF}(f, z)
$$

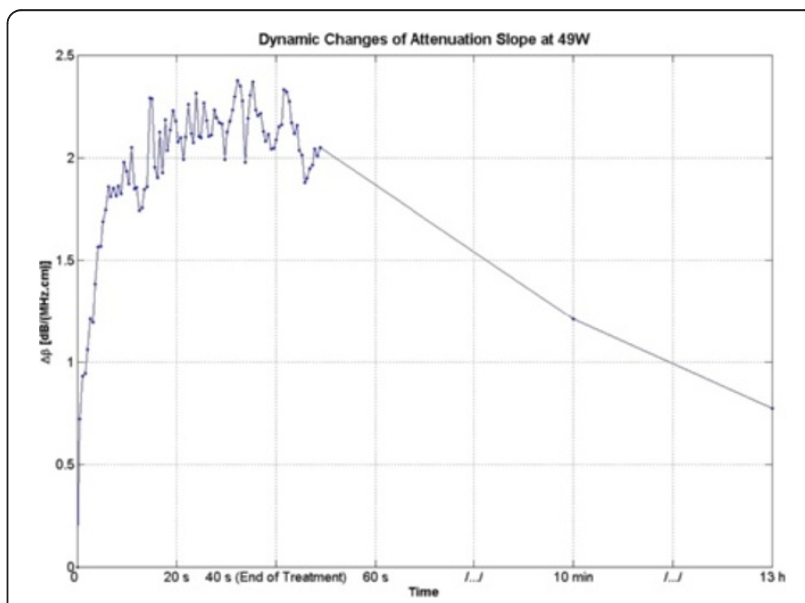

Figure 6 Dynamic changes of $\Delta \beta$ in ex vivo porcine muscle tissue during HIFU treatment. $\Delta \beta$ values were estimated by spatially averaging the $\Delta \beta$ values axially and laterally in the region of interest $(10 \mathrm{~mm} \times 10 \mathrm{~mm})$ centered around the lesion generated by HIFU beam. The duty cycle was $77 \%$, resulting in TAP of $49 \mathrm{~W}$ and average focal intensity of $1,068 \mathrm{~W} / \mathrm{cm}^{2}$ at the HIFU treatment site, for a total HIFU treatment time of $40 \mathrm{~s}$. 


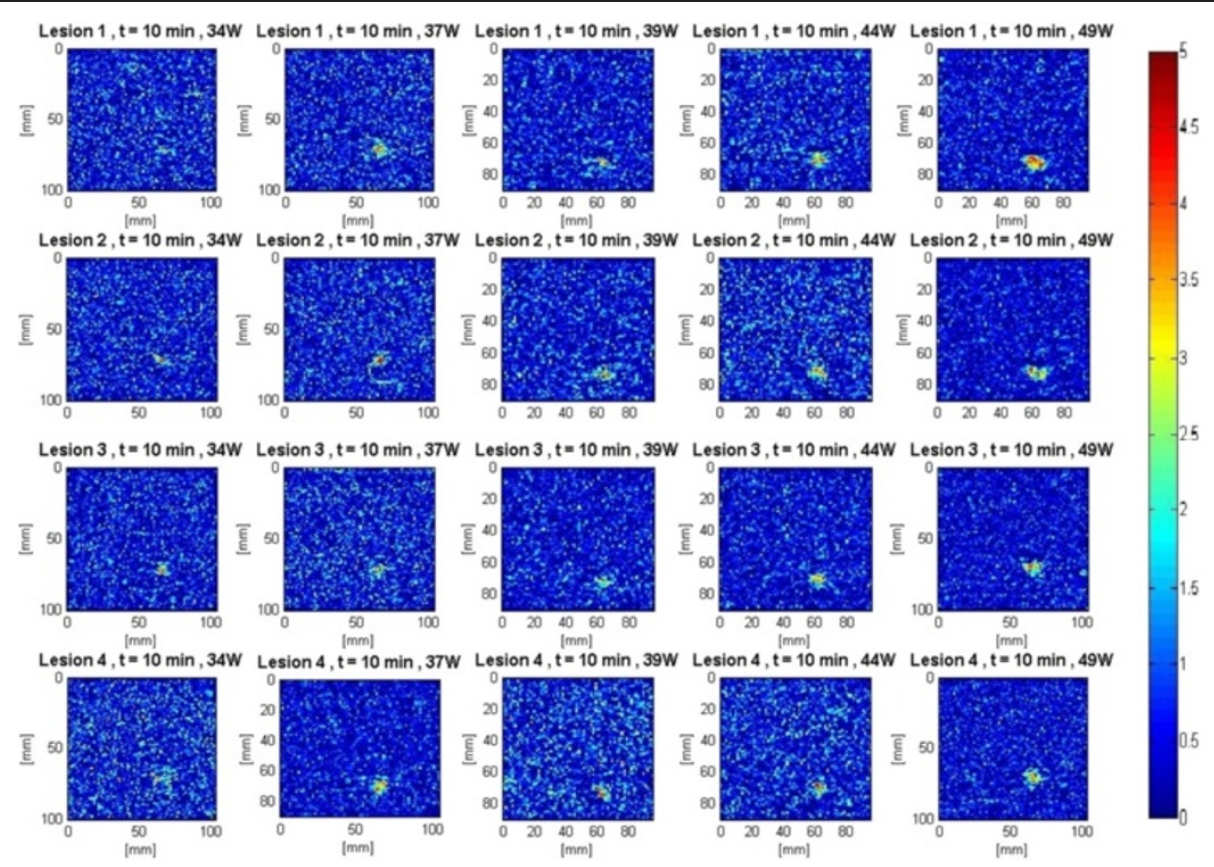

Figure $\mathbf{7} \Delta \boldsymbol{\beta}$ images detecting lesions in ex vivo porcine muscle tissues at $\mathbf{1 0}$ min posttreatment. The duty cycle was $77 \%$, resulting in TAP values of $34,37,39,44$, and $49 \mathrm{~W}$, for HIFU treatment time of $40 \mathrm{~s}$. A total of four lesions were created at every power level.

$$
\begin{aligned}
& \ln P(f, z)_{\text {signal }}=\ln P_{0}(f)+\ln \exp \left[2 \cdot \gamma_{\mathrm{T}}(f) \cdot z\right] \\
& \ln P(f, z)_{\text {signal }}=\ln P_{0}(f)+2 \cdot \gamma_{\mathrm{T}}(f) \cdot z \\
& S_{\text {signal }}(f)=-\operatorname{Re}\left\{\ln P_{0}(f)+2 \cdot \gamma_{\mathrm{T}}(f) \cdot z\right\} .
\end{aligned}
$$

Substituting $\gamma_{\mathrm{T}}(f)=-\alpha(f)-i \delta(f)$ in Equation 19a yields

$$
S_{\text {signal }}(f)=-\operatorname{Re}\left\{\ln P_{0}(f)\right\}+2 . \alpha(f)_{\text {signal }} . z .
$$

Similarly, the reference obtained at $t_{0}(t=0 \mathrm{~s})$ is

$$
\begin{aligned}
S_{\text {reference }}(f)= & -\operatorname{Re}\left\{\ln P_{0}(f)+2 \cdot \gamma_{\mathrm{T}}(f) \cdot z\right\} \\
S_{\text {reference }}(f)= & -\operatorname{Re}\left\{\ln P_{0}(f)\right\} \\
& +2 \cdot \alpha_{\mathrm{a}}(f)_{\text {reference }} \cdot z .
\end{aligned}
$$

Subtracting $S_{\text {reference }}$ from $S_{\text {signal }}$ results in

$$
\begin{aligned}
\Delta S(f) & =S_{\text {signal }}(f)-S_{\text {reference }}(f) \\
\Delta S(f) & =2 \cdot z \cdot\left(\alpha_{\mathrm{a}}(f)_{\text {signal }}-\alpha_{\mathrm{a}}(f)_{\text {reference }}\right) \\
& =2 \cdot z \cdot \Delta \alpha_{\mathrm{a}}(f) .
\end{aligned}
$$

Based on Equation 16,

$$
\Delta S(f)=2 . z . \Delta \alpha(f)
$$

substituting $\alpha(f)=\alpha_{0}+\beta\left(f-f_{\mathrm{c}}\right)$,

$$
\begin{aligned}
& \Delta S(f)=2 . z \cdot\left(\Delta \alpha_{0}+\Delta \beta\left(f-f_{\mathrm{c}}\right)\right) \\
& \Delta S(f)=2 \cdot z \cdot \Delta \alpha_{0}+2 \cdot z \cdot \Delta \beta \cdot\left(f-f_{\mathrm{c}}\right)
\end{aligned}
$$

Fitting a line to $\Delta S(f)$ and then diving the slope of the fitted line by $2 z$ yields $\Delta \beta$.

The attenuation intercept algorithm was implemented to estimate $\Delta \alpha_{0}$ using identical steps. However, after the acquisition of $\Delta S(f)$ (Equation 21e), the value of $\Delta S(f)$ at the center frequency, $f_{\mathrm{c}}$, is evaluated as follows:

$$
\begin{aligned}
& \Delta S\left(f_{\mathrm{c}}\right)=2 \cdot z \cdot \Delta \alpha_{0}+2 \cdot z \cdot \Delta \beta \cdot\left(f_{\mathrm{c}}-f_{\mathrm{c}}\right) \\
& \Delta S\left(f_{\mathrm{c}}\right)=2 \cdot z \cdot \Delta \alpha_{0} \\
& \frac{\Delta S\left(f_{\mathrm{c}}\right)}{2 . z}=\frac{2 \cdot z \cdot \Delta \alpha_{0}}{2 \cdot z}=\Delta \alpha_{0} .
\end{aligned}
$$

$\Delta \alpha_{0}$ and $\Delta \beta$ were estimated using a moving Blackman window function of length $5 \lambda$, with $\lambda=\frac{\mathrm{c}}{f_{\mathrm{c}}}$, where $f_{\mathrm{c}}$ was the imaging center frequency (during this study $f_{\mathrm{c}}=4$ $\mathrm{MHz}$ ). The moving window was shifted by (2.5) $\lambda$ at every iteration, resulting in $\Delta z=0.96 \mathrm{~mm}$.

\section{Results}

Field profile analysis and efficiency of the HIFU transducer

Based on hydrophone measurements and ultrasound beam computer simulation results, the axial and lateral focal widths of the HIFU beam were measured to be 2 

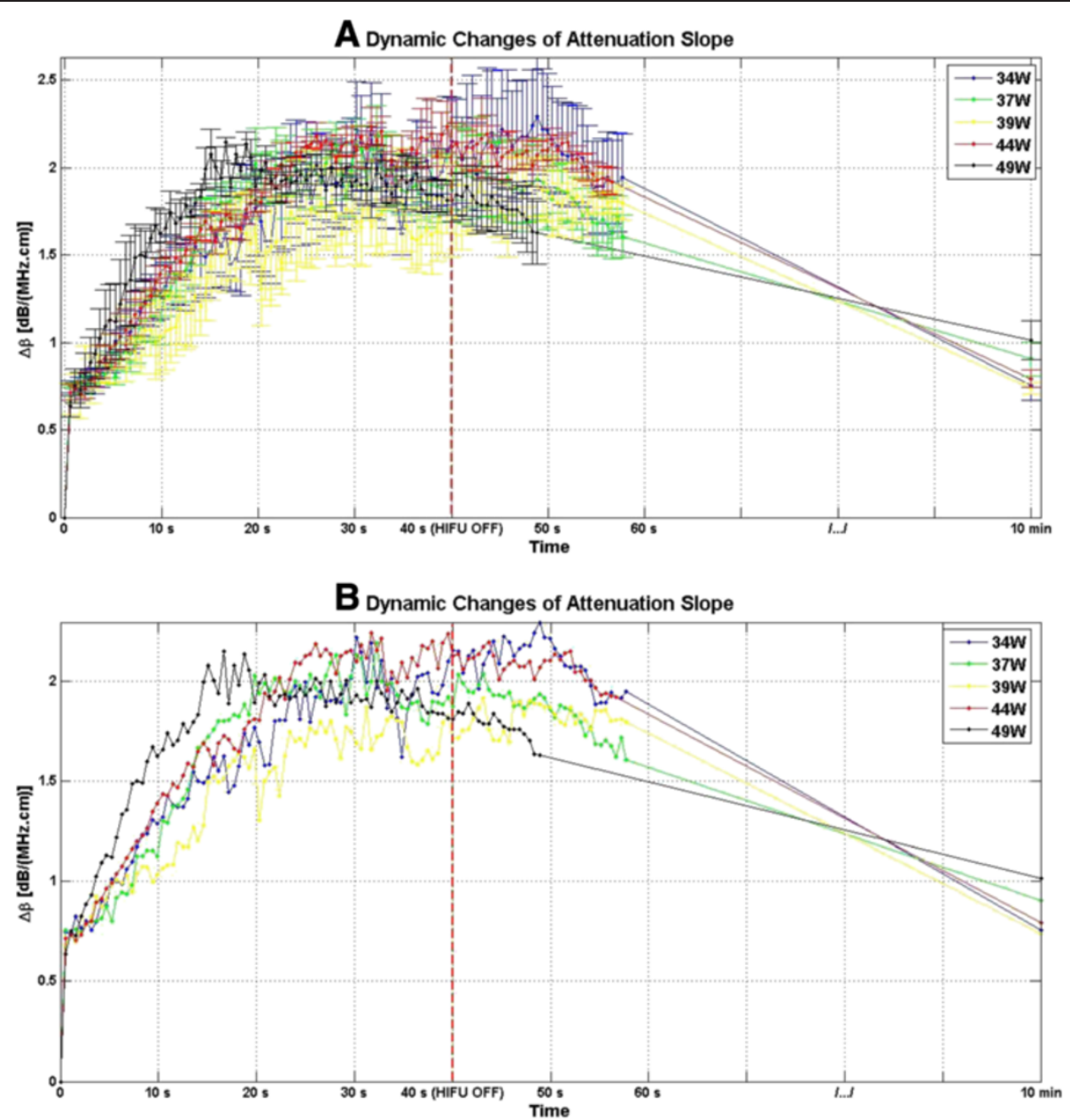

Figure 8 Dynamic changes of $\Delta \beta$ in ex vivo porcine muscle tissue during HIFU treatment. (A) A total of four lesions were created at every TAP. $\Delta \beta$ values for each lesion were estimated by spatially averaging the $\Delta \beta$ values in ROI, and then those values were further averaged with each other, generating an average profile for each TAP value. For a monitoring duration of 10 min, the duty cycle was $77 \%$, resulting in TAP values of 34, 37, 39, 44, and $49 \mathrm{~W}$, for HIFU treatment time of $40 \mathrm{~s}$. (B) Dynamic changes of $\Delta \beta$ in ex vivo porcine muscle tissue during HIFU treatment presented without the error bars.

and $8 \mathrm{~mm}$ at FWHM, respectively. The computer simulations were conducted for a TAP value of $1 \mathrm{~W}$ at the surface of the HIFU transducer.

For input electric powers in the range of 0.8 and $157 \mathrm{~W}$, the efficiency of the transducer was measured to be $64 \%$. Table 1 is a summary of the input electric powers with the corresponding TAP values and free-field spatially averaged intensities. $I_{\mathrm{SA}}$ were estimated using Equation 1 for a duty cycle of $77 \%$ and maximum beam width at FWHM of $2 \mathrm{~mm}$.

\section{Changes in attenuation slope $(\Delta \beta)$}

The visualization of lesion formation was directly correlated with the B-mode images formed from the pulseecho RF data, shown in Figure 4A. The induced lesion (Figure 4B) was monitored for $13 \mathrm{~h}$. Figure 5 shows the corresponding $\Delta \beta$ images generated using the same $\mathrm{RF}$ data, with every frame representing a 2-D map of change in least squares attenuation coefficient slope. As shown in Figure 4A, a bright hyperechoic region appeared at the focal region in the B-mode image at $2.6 \mathrm{~s}$ and then enlarged and grew in intensity during HIFU treatment. Corresponding to the hyperechoic region that appeared in the B-mode images, Figure 5 revealed a high-intensity region that appeared in the $\Delta \beta$ images at $2.6 \mathrm{~s}$ and then enlarged and grew in intensity during HIFU treatment. After the treatment, the bright hyperechoic region in the focal region of the B-mode image began to gradually fade, and after $10 \mathrm{~min}$, it was hardly visible in the Bmode images. After $13 \mathrm{~h}$, the hyperechoic region was virtually invisible in the B-mode image. Meanwhile, even after $13 \mathrm{~h}$, the high-intensity region in the $\Delta \beta$ image remained visible. However, this high-intensity region decreased in size and intensity after $10 \mathrm{~min}$ had passed, 

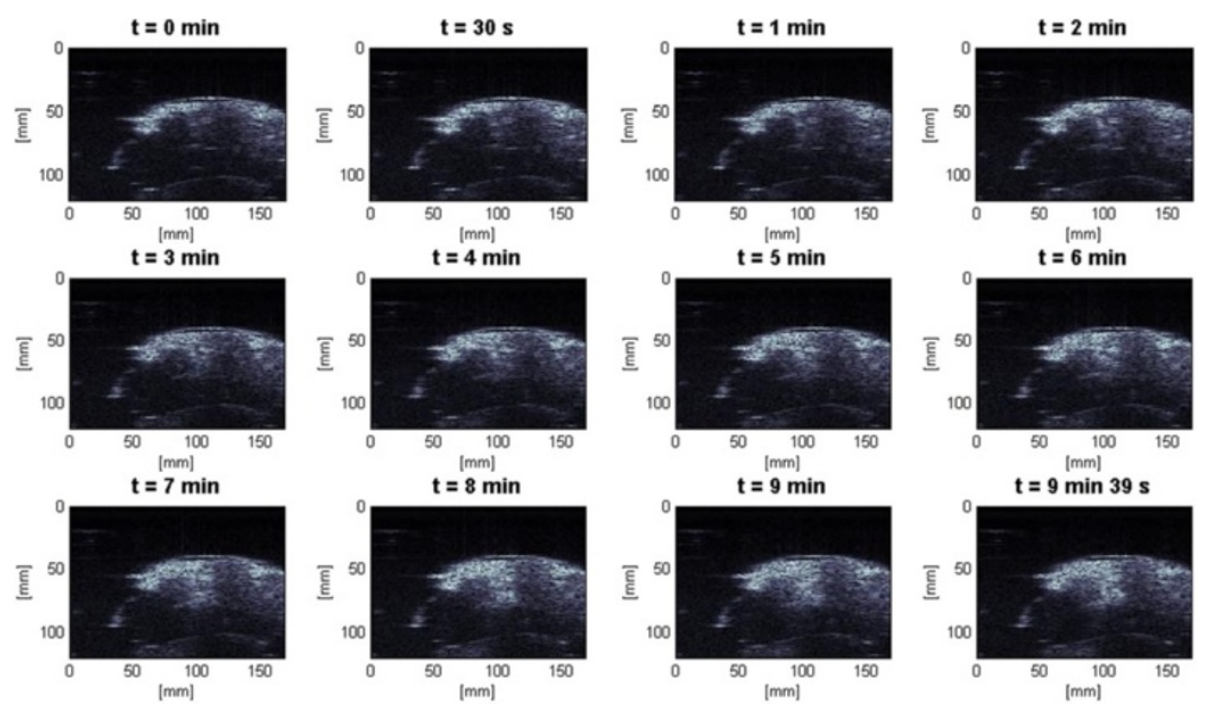

Figure 9 Lesion growth in ex vivo porcine muscle tissue in conventional B-mode images during slow HIFU. The slow HIFU experiment was conducted with a duty cycle of $77 \%$ and TAP of $5 \mathrm{~W}$, resulting in an average focal intensity of $117 \mathrm{~W} / \mathrm{cm}^{2}$ at the HIFU treatment site, for a total HIFU treatment time of 9 min and $39 \mathrm{~s}$. B-mode images were obtained continuously from the beginning of treatment to the end of treatment.

and after $13 \mathrm{~h}$, it decreased in size and intensity to a higher extent.

Figure 6 shows the dynamic changes of attenuation slope $(\Delta \beta)$ in the region of interest. $\Delta \beta$ values were estimated by spatially averaging the $\Delta \beta$ values axially and laterally in the region of interest $(10 \mathrm{~mm} \times 10 \mathrm{~mm})$ centered around the lesion generated by HIFU as shown in Figure 5 . As evident in Figure $6, \Delta \beta$ rose very rapidly in the first $20 \mathrm{~s}$ of treatment from 0 to $2 \mathrm{~dB} /(\mathrm{MHz} . \mathrm{cm})$ and stayed at
$2 \mathrm{~dB} /(\mathrm{MHz} . \mathrm{cm})$ with some fluctuations for the next $20 \mathrm{~s}$ until the end of HIFU treatment at $40 \mathrm{~s}$. After treatment, $\Delta \beta$ gradually decreased, and at $10 \mathrm{~min}$, the $\Delta \beta$ algorithm detected a value of $1.3 \mathrm{~dB} /(\mathrm{MHz} . \mathrm{cm})$. At $13 \mathrm{~h}$, the $\Delta \beta$ algorithm detected a value of $0.75 \mathrm{~dB} /(\mathrm{MHz} . \mathrm{cm})$.

The assumption that all bubble activities had completely vanished $10 \mathrm{~min}$ after the end of HIFU treatment $[39,40]$ was made. In addition, due to the heat transfer properties of soft biological tissues, it could be safely
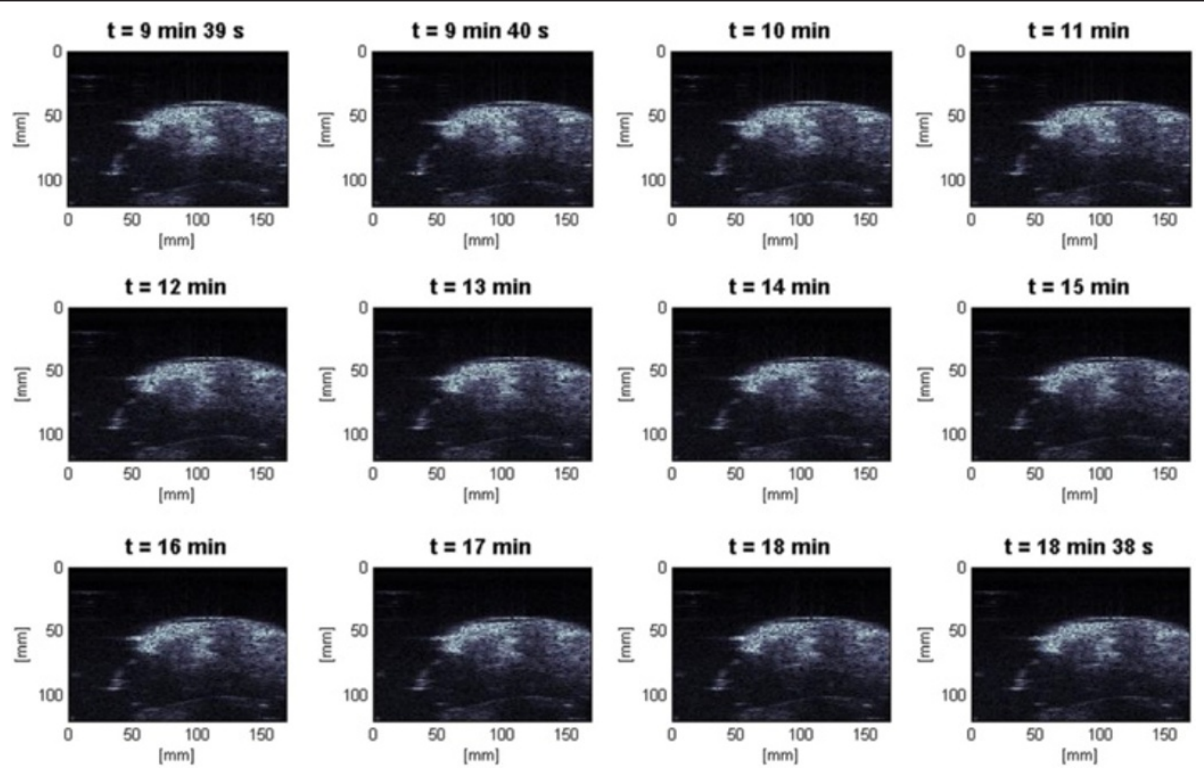

Figure 10 B-mode images during the cooling sequence. Induced lesion in ex vivo porcine muscle tissue in conventional B-mode images during the cooling cycle of the slow HIFU experiment. The B-mode images were obtained continuously until 9 min after the end of HIFU treatment. 


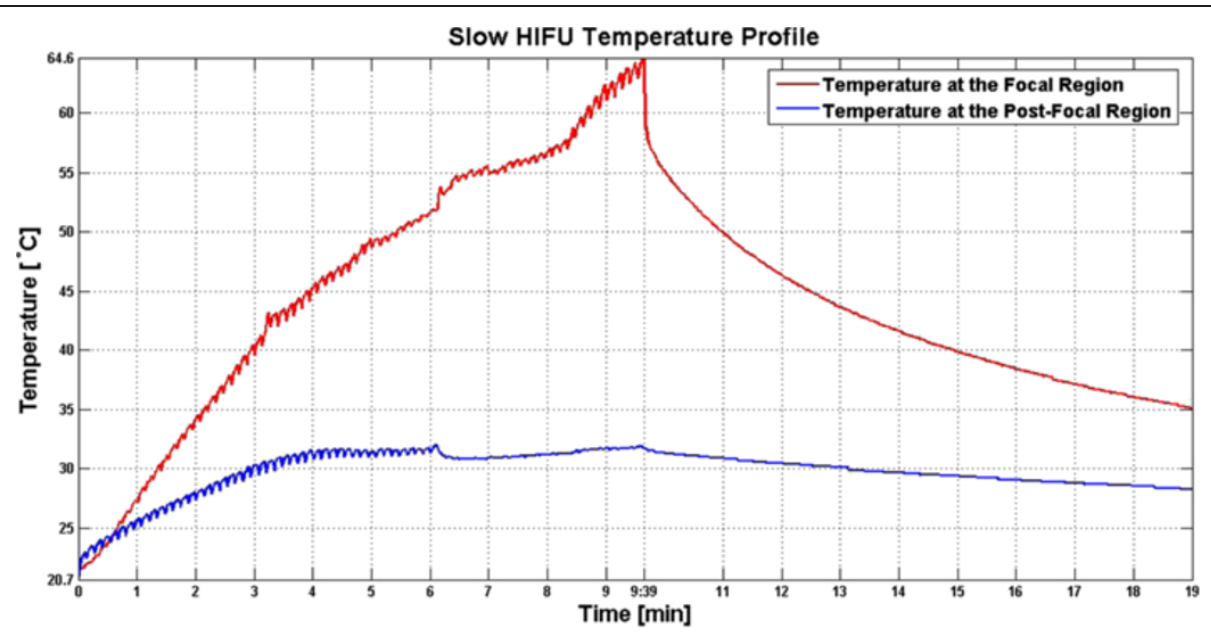

Figure 11 Temperature profile for the slow HIFU experiment. Temperature data were collected from the focal and post-focal regions of the tissue sample using two thermocouples for a duration of 19 min.
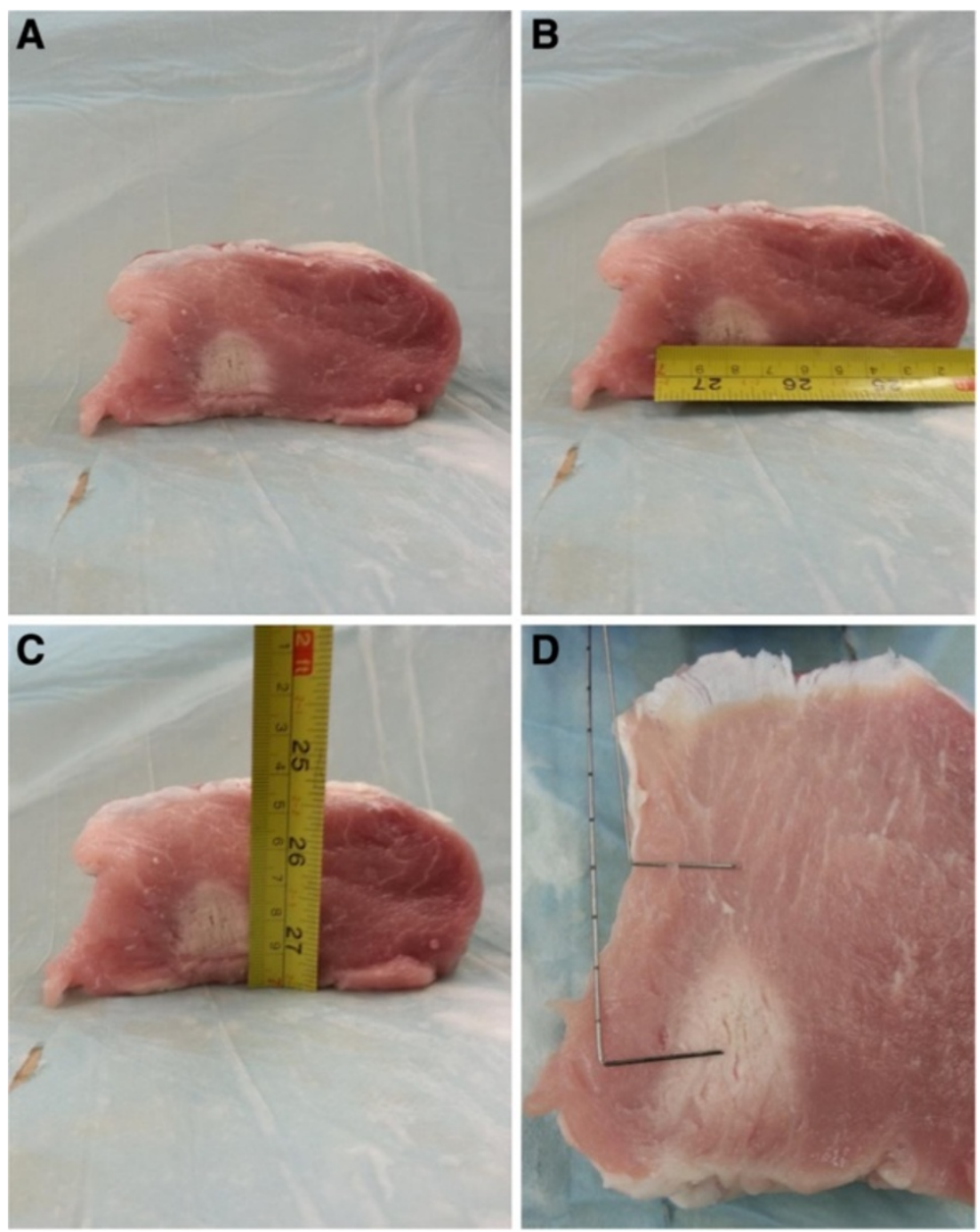

Figure 12 Induced lesion in ex vivo porcine muscle tissue resulting from exposure to slow HIFU. (A, B, C) Axial section of the lesion induced within the tissue sample, with the HIFU transducer sonicating from the bottom of the tissue. (D) A thin slice of tissue sample containing the axial section of the lesion induced, with the thermocouples showing the locations where temperature data were collected. 

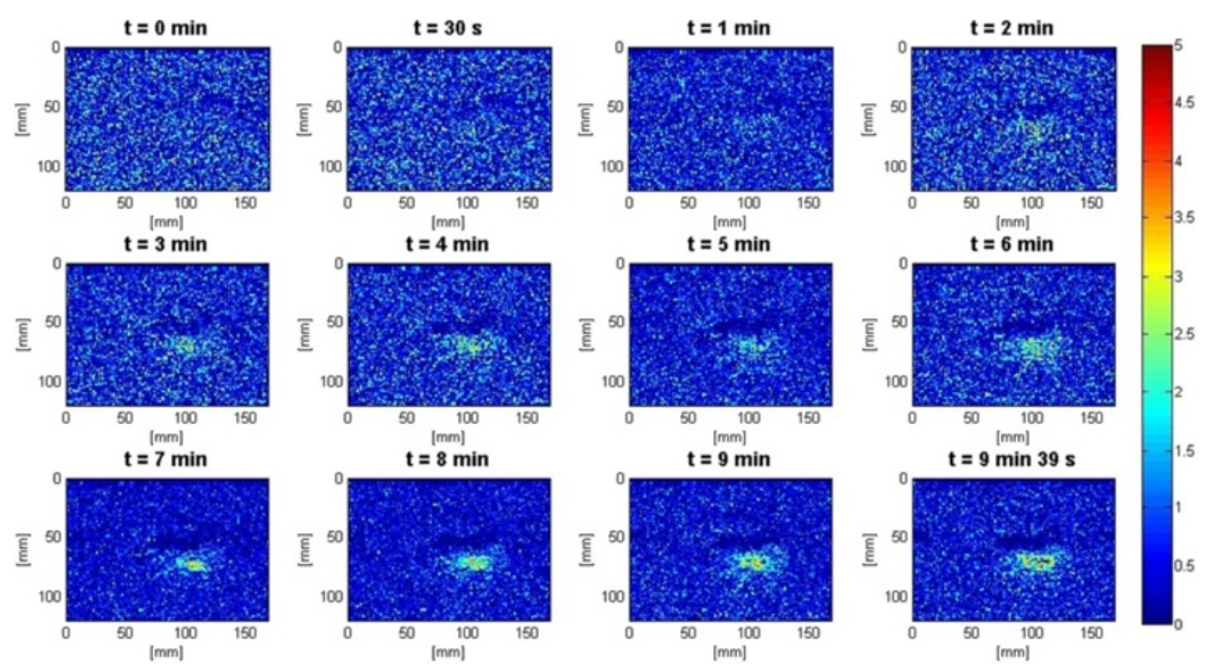

Figure 13 Lesion growth in ex vivo porcine muscle tissue in $\Delta \boldsymbol{\beta}$ images during slow HIFU. The slow HIFU experiment was conducted with a duty cycle of $77 \%$ and TAP of $5 \mathrm{~W}$, resulting in an average focal intensity of $117 \mathrm{~W} / \mathrm{cm}^{2}$ at the HIFU treatment site, for a total HIFU treatment time of 9 min and $39 \mathrm{~s}$.

assumed that the temperature in the region of interest had cooled down to its pretreatment level. As a result, the output of the $\Delta \beta$ algorithm at 10 min was used to assess the performance of the algorithm in detecting tissue thermal damage in the absence of boiling bubbles and temperature rise. Figure 7 shows $\Delta \beta$ images generated by the attenuation slope algorithm at different TAP values $10 \mathrm{~min}$ after the end of treatment. A total of four lesions were created at every TAP. These $\Delta \beta$ images were used to assess the performance of the attenuation slope algorithm.

Figure 8 shows the dynamic changes of attenuation slope as a result of HIFU treatment in ex vivo porcine muscle tissue at different TAP values, for a duration of $10 \mathrm{~min}$. Figure 8 indicates that at all investigated TAP values, $\Delta \beta$ rose very rapidly in the first $20 \mathrm{~s}$ of treatment, from 0 to values in the range of $1.5-2 \mathrm{~dB} /(\mathrm{MHz} . \mathrm{cm})$ and then maintained its level within that range with some fluctuations over the next $20 \mathrm{~s}$ to the end of HIFU treatment at $40 \mathrm{~s}$. After the end of treatment, $\Delta \beta$ values gradually decreased, and after $10 \mathrm{~min}$, the $\Delta \beta$ algorithm resulted in values in the range of $0.75-1 \mathrm{~dB} /(\mathrm{MHz} / \mathrm{cm})$.

In the slow HIFU experiment, once again the visualization of lesion formation was directly correlated with the B-mode images formed from the pulse-echo RF data. Figure 9 represents the B-mode images obtained during
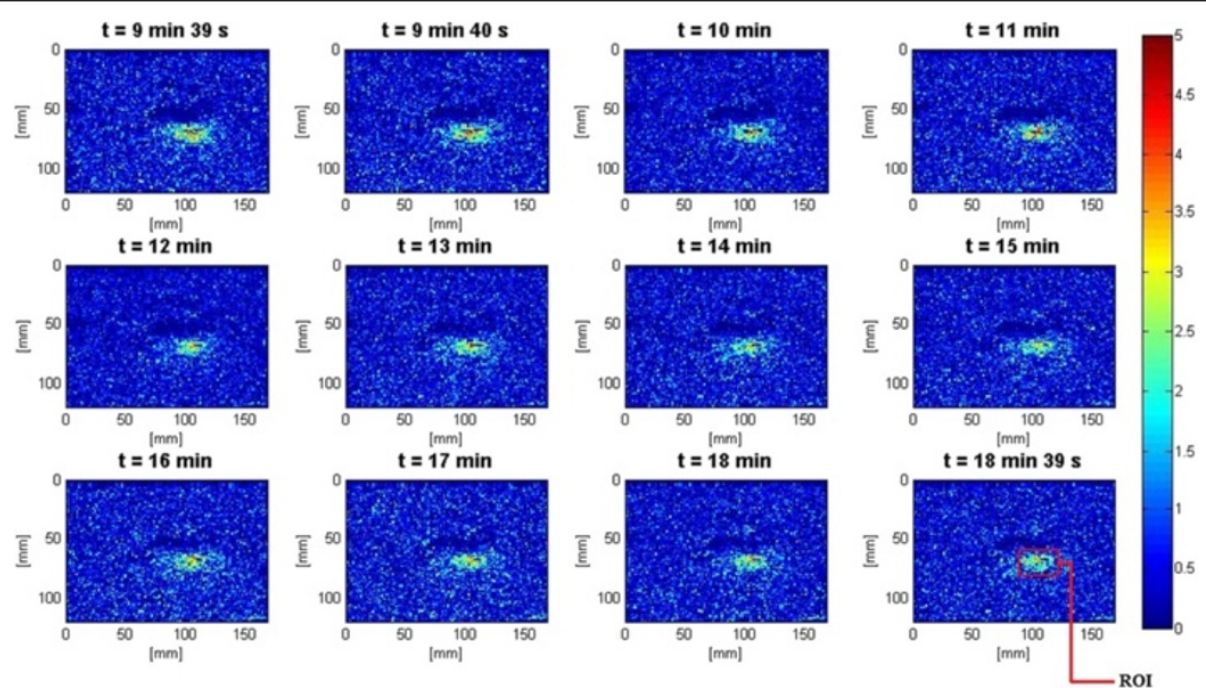

Figure $14 \Delta \beta$ images during the cooling cycle of the slow HIFU experiment. Induced lesion in ex vivo porcine muscle tissue in $\Delta \beta$ images during the cooling cycle of the slow HIFU experiment. The $\Delta \beta$ images were generated until 9 min after the end of the HIFU treatment. 


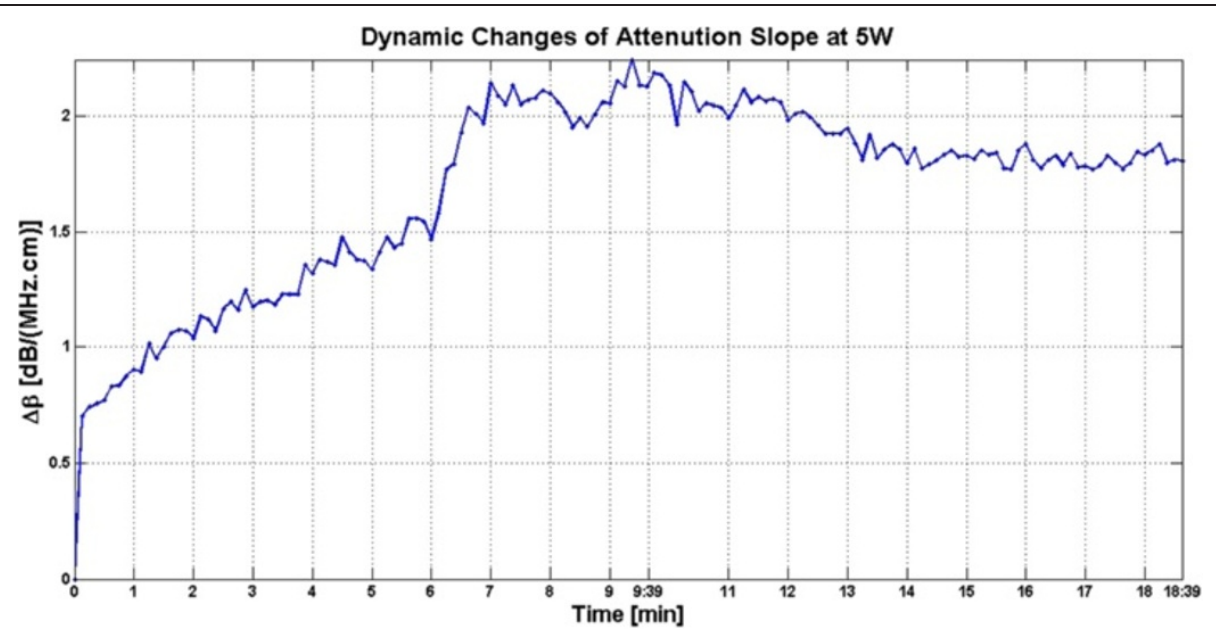

Figure 15 Dynamic changes of $\Delta \beta$ in ex vivo porcine muscle tissue during slow HIFU treatment. $\Delta \beta$ values were estimated by spatially averaging the $\Delta \beta$ values axially and laterally in the region of interest $(20 \mathrm{~mm} \times 34 \mathrm{~mm}$ ) centered around the lesion generated by HIFU as shown in Figure 14. The duty cycle was $77 \%$, with TAP of $5 \mathrm{~W}$, resulting in an average focal intensity of $117 \mathrm{~W} / \mathrm{cm}^{2}$ at the HIFU treatment site, for a total HIFU treatment time of 9 min and $39 \mathrm{~s}$.

the heating sequence from the start of treatment to the end of treatment at $9 \mathrm{~min}$ and $39 \mathrm{~s}$. Figure 10 represents the B-mode images during the cooling sequence obtained until 9 min from the end of the treatment. Figure 11 represents the temperature profile at the focal and post-focal regions of the tissue sample, and Figure 12 represents the induced lesion. Figures 13 and 14 show the corresponding $\Delta \beta$ images generated using the same RF data. Unlike in Figure $4 \mathrm{~A}$, the bright hyperechoic region at the focal region in the B-mode image was not present. However, once again, Figures 13 and 14 revealed a high-intensity region that appeared in the $\Delta \beta$ images at $3 \mathrm{~min}$ and then enlarged and grew in intensity during HIFU treatment. The highintensity region in the $\Delta \beta$ images remained visible during the cooling cycle. However, it slightly decreased in size and intensity after $9 \mathrm{~min}$ had passed.

Figure 15 shows the dynamic changes of attenuation slope $(\Delta \beta)$ in the region of interest during the slow HIFU exposure. $\Delta \beta$ maps were generated by spatially averaging the $\Delta \beta$ values axially and laterally in the region of interest $(20 \mathrm{~mm} \times 34 \mathrm{~mm})$ centered around the lesion generated by HIFU as shown in Figure 14. As evident in Figure 15, $\Delta \beta$ rose gradually in the first 6 min of treatment from 0 to $1.5 \mathrm{~dB} /(\mathrm{MHz} . \mathrm{cm})$. From 6 to $7 \mathrm{~min}$, there was a jump in

Table $2 \Delta \beta$ values vs. total acoustic power at $t=10 \mathrm{~min}$

\begin{tabular}{cc}
\hline Total acoustic power $(\mathrm{W})$ & $\boldsymbol{\Delta} \boldsymbol{\beta}(\mathrm{dB} /(\mathbf{M H z} . \mathbf{c m}))$ \\
\hline 5 & $1.81 \pm 0.05$ \\
34 & $0.76 \pm 0.09$ \\
37 & $0.91 \pm 0.10$ \\
39 & $0.74 \pm 0.03$ \\
44 & $0.79 \pm 0.05$ \\
49 & $1.01 \pm 0.11$ \\
\hline
\end{tabular}

the value of $\Delta \beta$ from 1.5 to $2.1 \mathrm{~dB} /(\mathrm{MHz} . \mathrm{cm}) . \Delta \beta$ maintained its value around $2.1 \mathrm{~dB} /(\mathrm{MHz} . \mathrm{cm})$ with some fluctuations until the end of HIFU treatment at $9 \mathrm{~min}$ and $39 \mathrm{~s}$ when it reached a maximum value of $2.2 \mathrm{~dB} /(\mathrm{MHz}$. $\mathrm{cm})$. After treatment, $\Delta \beta$ gradually decreased to $1.8 \mathrm{~dB} /$ $(\mathrm{MHz} . \mathrm{cm})$ and remained stable at that value. Once again, the output of the $\Delta \beta$ algorithm at the end of the treatment was used to assess the performance of the algorithm in detecting tissue thermal damage in the absence of boiling bubbles and temperature rise. Table 2 summarizes the resulting $\Delta \beta$ values in the region of interest (ROI), for different TAP values, approximately $10 \mathrm{~min}$ after HIFU treatment.

\section{Changes in attenuation intercept $\left(\Delta a_{0}\right)$}

The attenuation intercept algorithm was used on the same set of RF data that was used for the attenuation slope algorithm in the previous section. Once again the visualization of lesion formation was directly correlated with the B-mode images (Figure 4). Figure 16 shows the corresponding $\Delta \alpha_{0}$ images, with every frame representing a 2-D map of change in attenuation coefficient intercept $\left(\Delta \alpha_{0}\right)$. Similar to previous results, corresponding to the hyperechoic region that appeared in the B-mode images at $t=2.6 \mathrm{~s}$, a high-intensity region appeared in the $\Delta \alpha_{0}$ images at $2.6 \mathrm{~s}$ (Figure 16). Once again this high-intensity region enlarged and grew in intensity during HIFU treatment. Thirteen hours after the treatment, the highintensity region in the $\Delta \alpha_{0}$ images still remained visible. In an outcome similar to $\Delta \beta$ images, the high-intensity region decreased in size and intensity after $10 \mathrm{~min}$ had passed, and after $13 \mathrm{~h}$, it decreased in size and intensity to a higher extent. $\Delta \alpha_{0}$ values were estimated by spatially averaging the $\Delta \alpha_{0}$ values axially and laterally in the region 

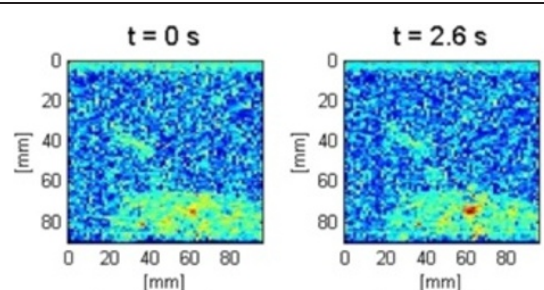

$t=16.64 s$
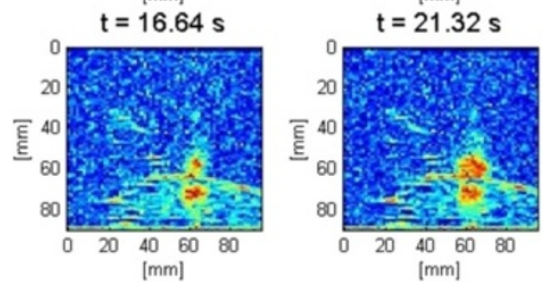

$\mathrm{t}=40.56 \mathrm{~s}$
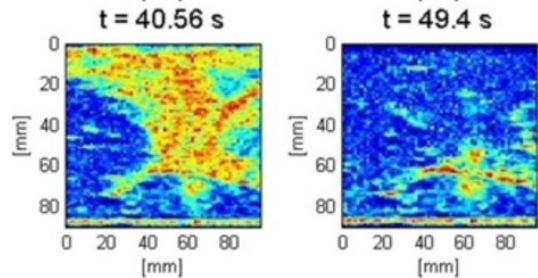

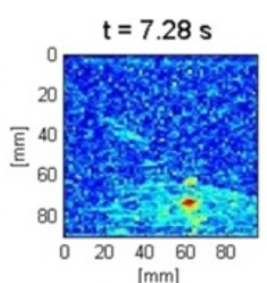

$t=26.0$

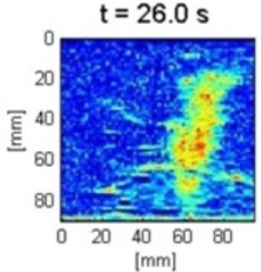

$\mathrm{t}=10 \mathrm{~min}$

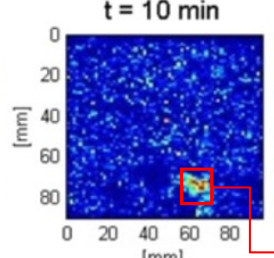

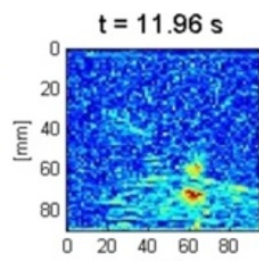

[mm]

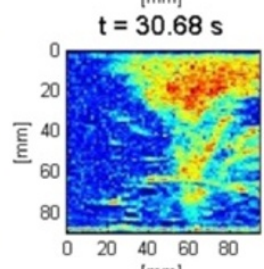

[mm]

$t=13 h$

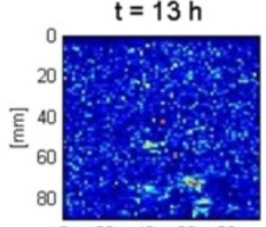

$\begin{array}{llll}20 & 40 & 60 & 80 \\ {[\mathrm{~mm}]} & \end{array}$

Figure 16 Lesion growth in ex vivo porcine muscle tissue in $\Delta \boldsymbol{a}_{0}$ images. The duty cycle was $77 \%$, resulting in TAP of $49 \mathrm{~W}$ and average focal intensity of $1,068 \mathrm{~W} / \mathrm{cm}^{2}$ at the HIFU treatment site, for a total HIFU treatment time of $40 \mathrm{~s}$.

of interest $(10 \mathrm{~mm} \times 10 \mathrm{~mm})$ centered around the lesion generated by HIFU as shown in Figure 16. Based on Figure $17, \Delta \alpha_{0}$ rose very rapidly in the first $20 \mathrm{~s}$ of treatment, from 0 to $5 \mathrm{~dB} / \mathrm{cm}$ and then stayed at $5 \mathrm{~dB} / \mathrm{cm}$ with some fluctuations over the next $20 \mathrm{~s}$ to the end of HIFU treatment at $40 \mathrm{~s}$. After treatment, $\Delta \alpha_{0}$ gradually decreased, and at $10 \mathrm{~min}$ posttreatment, the $\Delta \alpha_{0}$ algorithm

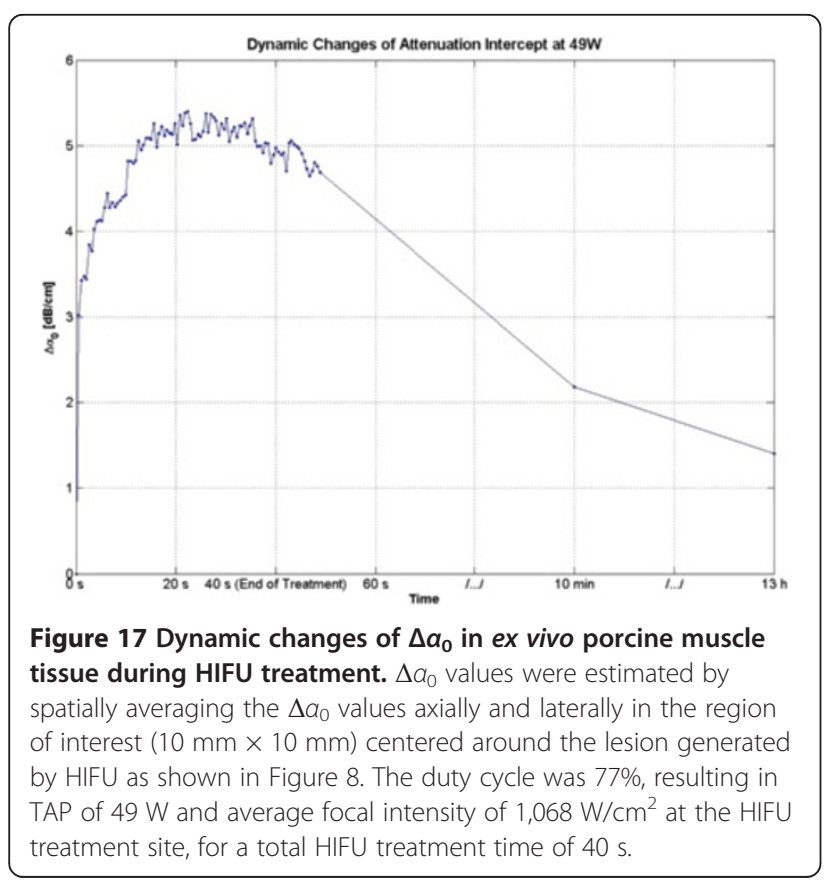

resulted in a value of approximately $2 \mathrm{~dB} / \mathrm{cm}$. At $13 \mathrm{~h}$, the $\Delta \alpha_{0}$ algorithm resulted in a value of $1.5 \mathrm{~dB} / \mathrm{cm}$.

Figure 18 shows $\Delta \alpha_{0}$ images generated by the attenuation intercept algorithm at different TAP values $10 \mathrm{~min}$ after the end of treatment. These $\Delta \alpha_{0}$ images were used to assess the performance of the attenuation intercept algorithm.

Figure 19 shows the dynamic changes of attenuation intercept as a result of HIFU treatment in ex vivo porcine muscle tissue at different TAP values. As evident in Figure 19, at all the investigated TAP values, $\Delta \alpha_{0}$ rose very rapidly in the first $20 \mathrm{~s}$ of treatment, from 0 to somewhere in the range of $4-5 \mathrm{~dB} / \mathrm{cm}$ and then maintained its value within that range with some fluctuations over the next $20 \mathrm{~s}$ to the end of HIFU treatment at $40 \mathrm{~s}$. After the end of treatment, $\Delta \alpha_{0}$ gradually decreased, and after10 $\mathrm{min}$, the $\Delta \alpha_{0}$ algorithm resulted in values in the range of $1-1.6 \mathrm{~dB} / \mathrm{cm}$.

In the slow HIFU experiment, once again the visualization of lesion formation was directly correlated with the B-mode images formed from the pulse-echo RF data. Figures 20 and 21 show the corresponding $\Delta \alpha_{0}$ images generated using the same RF data during the slow HIFU treatment experiment. Once again, Figures 20 and 21 revealed a high-intensity region that appeared in the $\Delta \alpha_{0}$ images at $3 \mathrm{~min}$ and then enlarged and grew in intensity during HIFU treatment. The high-intensity region in the $\Delta \alpha_{0}$ images remained visible during the cooling cycle and revealed minor amounts of decrease in size and intensity after $9 \mathrm{~min}$ had passed. Figure 22 shows the dynamic changes of attenuation intercept $\left(\Delta \alpha_{0}\right)$ in the 


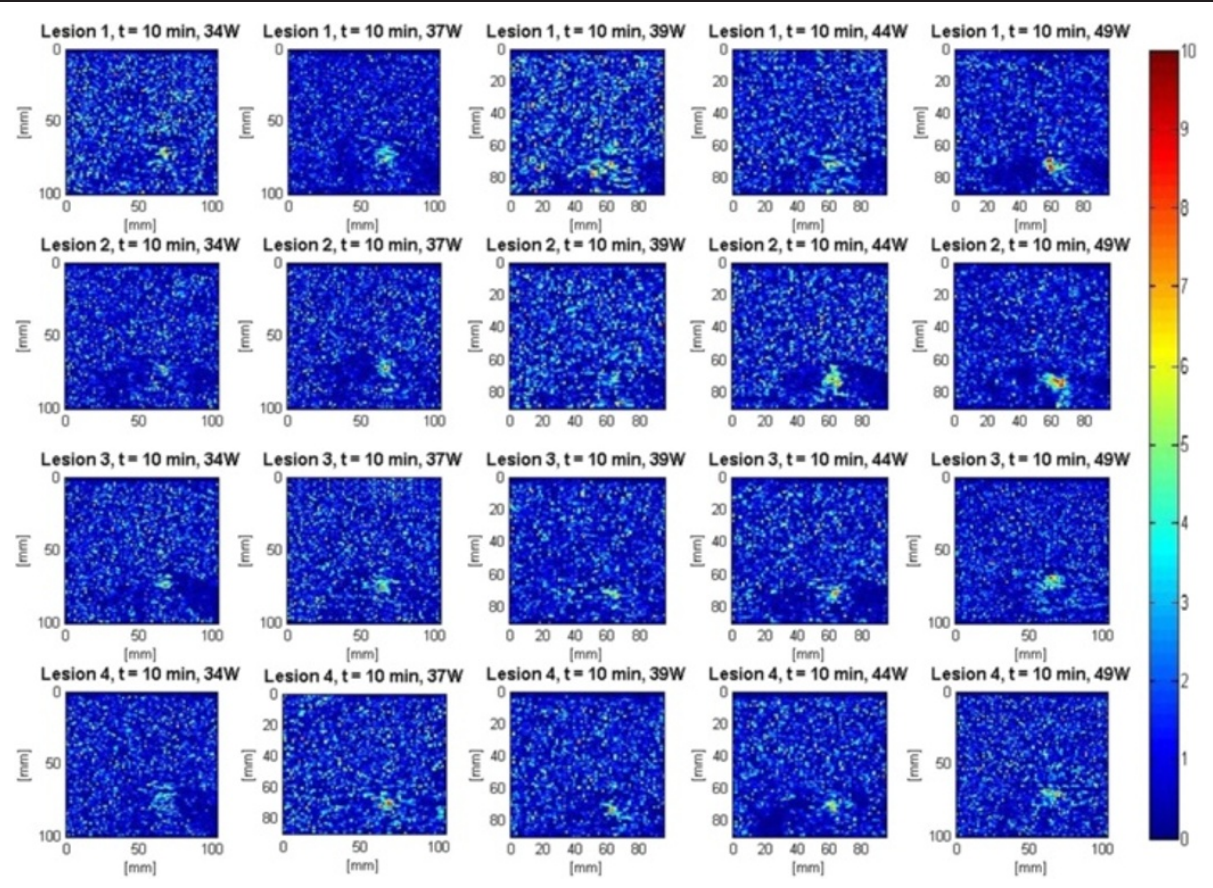

Figure $18 \Delta a_{0}$ images detecting lesions in ex vivo porcine muscle tissues at $\mathbf{1 0}$ min post treatment. The duty cycle was $77 \%$, resulting in TAPs of $34,37,39,44$, and $49 \mathrm{~W}$ for a HIFU treatment time of $40 \mathrm{~s}$. A total of four lesions were created at every power level.

region of interest. $\Delta \alpha_{0}$ maps were generated by spatially averaging the $\Delta \alpha_{0}$ values axially and laterally in the region of interest $(20 \mathrm{~mm} \times 34 \mathrm{~mm})$ centered around the lesion generated by HIFU as shown in Figure 21. As evident in Figure 22, $\Delta \alpha_{0}$ rose gradually in the first 6 min of treatment from 0 to $1.7 \mathrm{~dB} / \mathrm{cm}$. From 6 to $7 \mathrm{~min}$, there was a jump in the value of $\Delta \beta$ from 1.7 to $2 \mathrm{~dB} / \mathrm{cm} . \Delta \alpha_{0}$ maintained its value around $2 \mathrm{~dB} / \mathrm{cm}$ with minor fluctuations until the end of HIFU treatment at 9 min and 39 $\mathrm{s}$ when it reached a maximum value of $2.2 \mathrm{~dB} / \mathrm{cm}$. After treatment, $\Delta \alpha_{0}$ gradually decreased to $1.5 \mathrm{~dB} / \mathrm{cm}$ and remained stable at that value. Once again, the output of the $\Delta \alpha_{0}$ algorithm at the end of the treatment was used to assess the performance of the algorithm in detecting tissue thermal damage in the absence of boiling bubbles and temperature rise. Table 3 summarizes the resulting $\Delta \alpha_{0}$ values in the ROI, for different TAP values, approximately $10 \mathrm{~min}$ after HIFU treatment.

\section{Attenuation maps vs. conventional B-mode images}

To quantitatively compare the performance of the attenuation slope $(\Delta \beta)$ and attenuation intercept $\left(\Delta \alpha_{0}\right)$ algorithms with each other and with conventional Bmode imaging, the contrast-to-speckle ratios (CSR) [41] of these three different modes of generating images in this study were investigated. The CSR of an image is defined as [41]

$$
\operatorname{CSR}=\frac{S_{\text {in }}-S_{\text {out }}}{\sqrt{\sigma_{\text {in }}^{2}+\sigma_{\text {out }}^{2}}}
$$

where $S_{\text {in }}$ is the mean signal measured inside the region of interest, $S_{\text {out }}$ is the mean signal measured from samesized regions outside the region of interest, and $\sigma_{\text {in }}^{2}$ and $\sigma_{\text {out }}^{2}$ represent the variances of the signal within and outside the region of interest, respectively [41]. CSR values were calculated for the frames that were acquired $10 \mathrm{~s}$ after the end of HIFU treatment and for frames that were acquired $10 \mathrm{~min}$ after the end of treatment (Figure 23).

For the slow HIFU experiment, the CSR values were similarly calculated at $10 \mathrm{~s}$ after the end of the HIFU treatment and $9 \mathrm{~min}$ after the end of treatment. The results were separately tabulated in Table 4 .

\section{Discussions}

It has been postulated that bubbles are usually formed soon after the beginning of HIFU exposure at the HIFU treatment site $[3,42]$. These bubbles are either induced due to acoustic cavitation effects when the temperatures are still not high enough (referred to as cavitation bubbles) or due to boiling effects when the temperatures are sufficiently high (referred to as boiling bubbles) [3,42]. Boiling bubbles are highly scattering and sufficiently large that in ultrasound B-mode images they are clearly visible as bright hyperechoic regions at the HIFU treatment site 

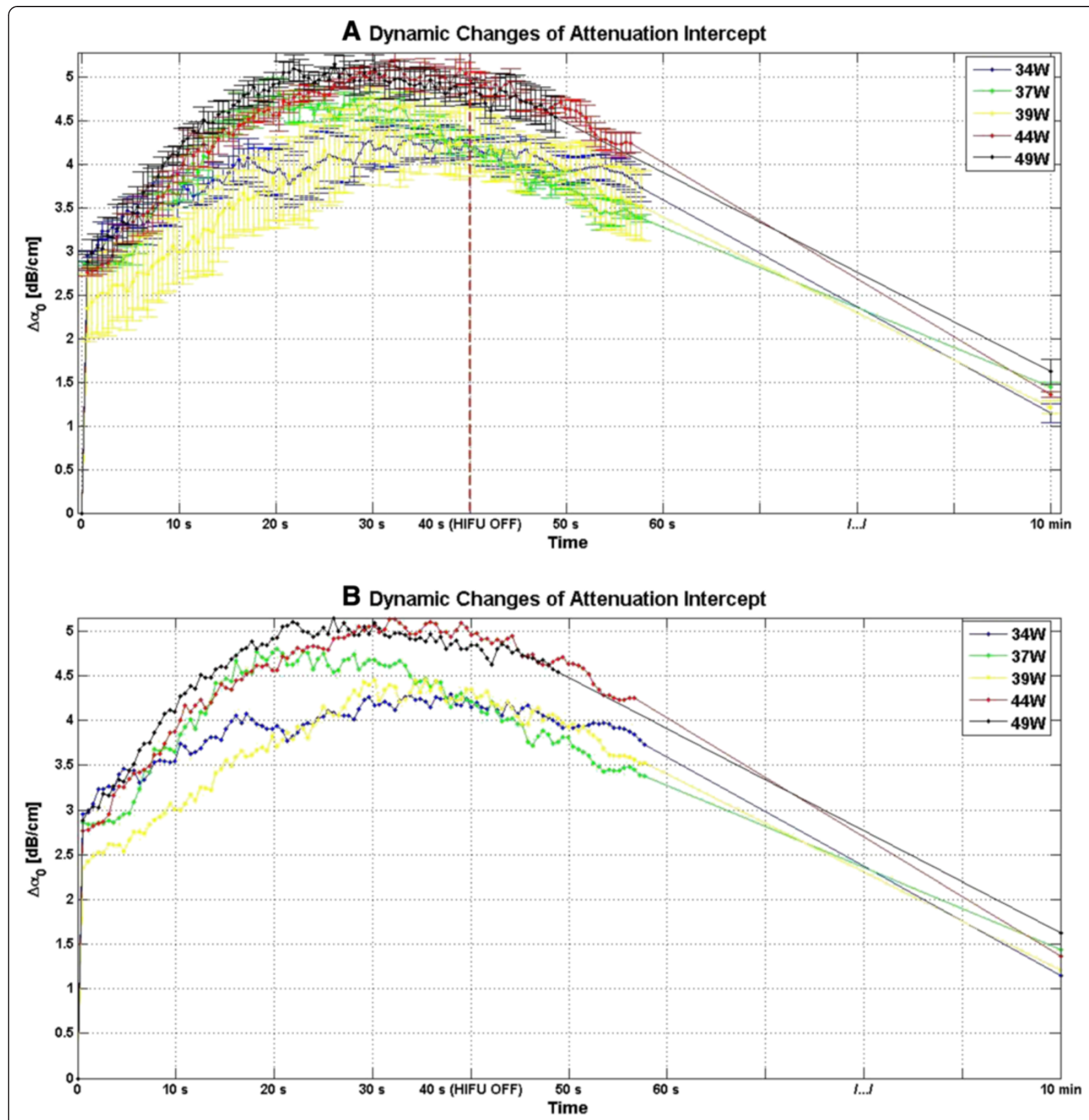

Figure 19 Dynamic changes of $\Delta a_{0}$ in ex vivo porcine muscle tissue during HIFU treatment. (A) A total of four lesions were created at every TAP. $\Delta a_{0}$ values for each lesion were estimated by spatially averaging the $\Delta a_{0}$ values in the ROI, and then those values were further averaged with each other generating an average profile for each TAP value. For monitoring duration of 10 min, the duty cycle was $77 \%$, resulting in TAP values of 34, 37, 39, 44, and 49 W, for a HIFU treatment time of 40 s. (B) Dynamic changes of $\Delta a_{0}$ in ex vivo porcine muscle tissue during HIFU treatment presented without the error bars.

$[39,42]$. Previous studies on transparent tissue-mimicking phantoms have shown the presence of violent bubble activities at the HIFU treatment site mainly due to boiling effects [34]. In our study, at higher HIFU intensities $\left(737-1,068 \mathrm{~W} / \mathrm{cm}^{2}\right)$, as soon as the HIFU was turned on, bright hyperechoic regions appeared in the B-mode images and then faded rapidly after HIFU was turned off (Figure 4A). Given the intensities at the HIFU treatment site and the fact that the tissue samples used in those experiments were not vacuum pumped, the bubble activities were probably mainly due to boiling effects.

During HIFU treatment, significant increases in values of $\beta$ and $\alpha_{0}$ were observed in lesions created in ex vivo 

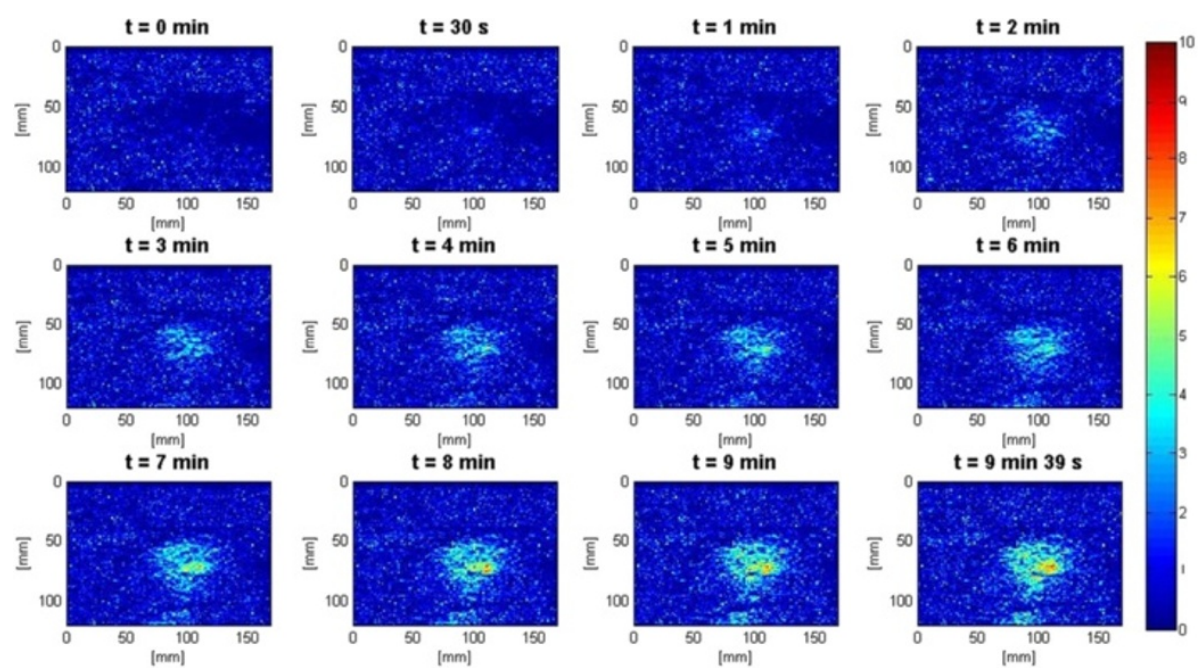

Figure 20 Lesion growth in ex vivo porcine muscle tissue in $\Delta a_{0}$ images during slow HIFU experiment. The slow HIFU experiment was conducted with a duty cycle of $77 \%$ and TAP of $5 \mathrm{~W}$, resulting in an average focal intensity of $117 \mathrm{~W} / \mathrm{cm}^{2}$ at the HIFU treatment site, for a total HIFU treatment time of $9 \mathrm{~min}$ and $39 \mathrm{~s}$.

porcine muscle tissues. These results agreed with previous results by similar studies [34]. The presence of bubble activities was detected simultaneously with the presence of hyperechoic regions in the B-mode images. Therefore, the rapid increases in $\Delta \beta$ and $\Delta \alpha_{0}$ and their consequent fluctuations (Figures 8 and 19) may be attributed to bubble activities causing abrupt changes in acoustic properties of the tissue at the HIFU treatment site. In one possible scenario, the formation of bubbles at the HIFU treatment site may have amplified the tissue ultrasound scattering properties (as evidenced by the presence of hyperechoic regions). This rapid increase in scattering of tissue at the HIFU treatment site significantly undermines the simplifying assumption in our method that scattering properties would remain constant, leading to a rapid increase in the total attenuation of tissue at that location (Equation 12). Finally, it has been shown that as a result of temperature rise, tissue attenuation coefficient increases [24]. Therefore, the rapid temperature rise at the site of HIFU treatment may have contributed to the rapid increases in $\Delta \beta$ and $\Delta \alpha_{0}$ values as well.

After HIFU treatment, the hyperechoic regions in the $B$-mode images rapidly faded. Corresponding to B-mode images, the high-intensity regions in $\Delta \beta$ and $\Delta \alpha_{0}$ images began to decrease in size at a relatively slower rate, until they became stable at around $10 \mathrm{~min}$ after the end of
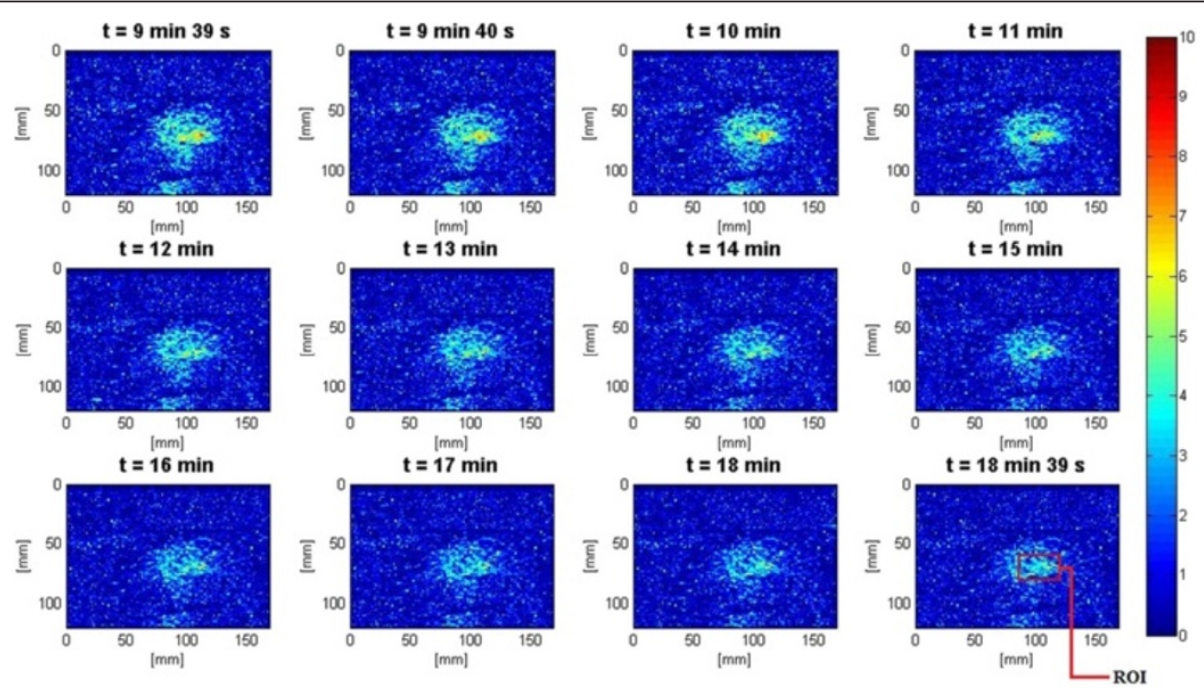

Figure $21 \Delta a_{0}$ images during the cooling cycle of the slow HIFU experiment. Induced lesion in ex vivo porcine muscle tissue in $\Delta a_{0}$ images during the cooling cycle of the slow HIFU experiment. The $\Delta \beta$ images were generated until 9 min after the end of the HIFU treatment. 


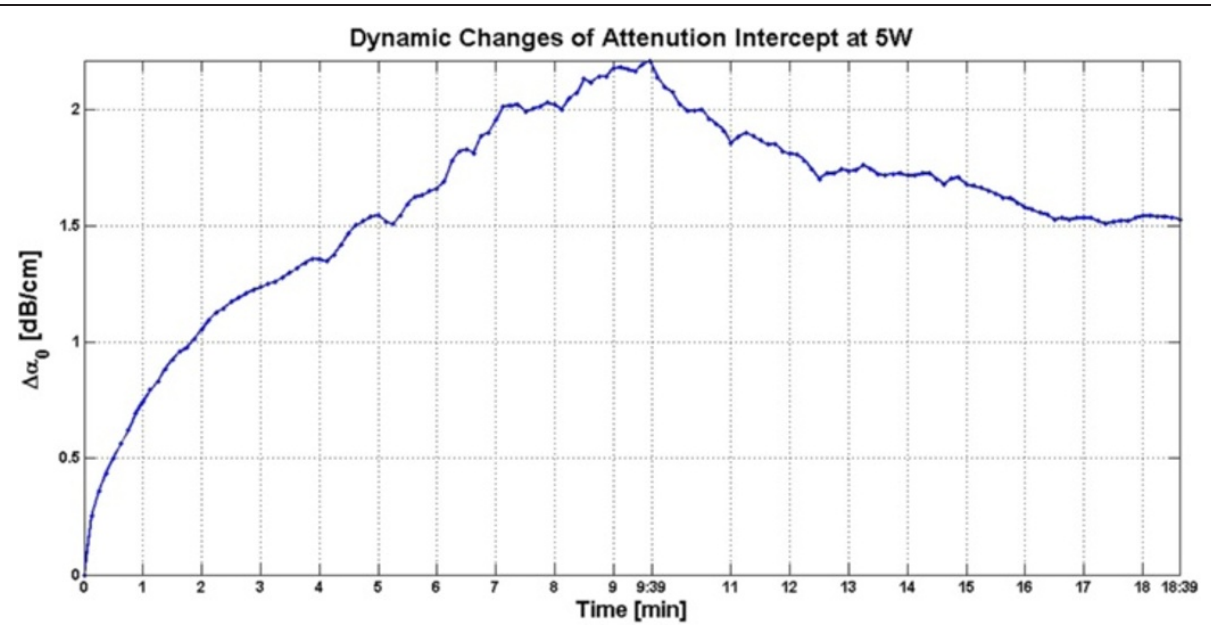

Figure 22 Dynamic changes of $\Delta a_{0}$ in ex vivo porcine muscle tissue during slow HIFU treatment. $\Delta a_{0}$ values were estimated by spatially averaging the $\Delta a_{0}$ values axially and laterally in the region of interest $(20 \mathrm{~mm} \times 34 \mathrm{~mm}$ ) centered around the lesion generated by HIFU as shown in Figure 14. The duty cycle was $77 \%$ with TAP of $5 \mathrm{~W}$, resulting in an average focal intensity of $117 \mathrm{~W} / \mathrm{cm}^{2}$ at the HIFU treatment site, for a total HIFU treatment time of $9 \mathrm{~min}$ and $39 \mathrm{~s}$.

treatment. This decrease in size may be attributed to the absence of bubbles long after the HIFU exposure and to the fact that the temperature at the site of HIFU exposure cools down to pretreatment levels. Thus, the highintensity regions detected in $\Delta \beta$ and $\Delta \alpha_{0}$ images at $10 \mathrm{~min}$ could be used as true representations of the boundaries of the coagulated regions of the tissue.

In the case of the lesion that was monitored overnight, it was observed that in $\Delta \beta$ and $\Delta \alpha_{0}$ images, the highintensity region further decreased in size and intensity from $10 \mathrm{~min}$ to $13 \mathrm{~h}$ after the end of HIFU treatment. This might be attributed to the fact that from $10 \mathrm{~min}$ to $13 \mathrm{~h}$, the temperature of the entire tissue and the focal spot significantly cooled down to below pretreatment levels. In addition, the tissue might have absorbed water from the water bath, resulting in changes in scattering properties of the tissue and the site of thermal damage and undermining our initial simplifying assumption regarding $\alpha_{\mathrm{s}}$.

During the slow HIFU experiment, the hyperechoic regions in the B-mode images did not appear at the same intensity and extent as before. This could be attributed to the special degassing process that was used and the significantly lower HIFU intensity at the treatment site $\left(117 \mathrm{~W} / \mathrm{cm}^{2}\right)$.

Table $3 \Delta a_{0}$ values vs. total acoustic power at $t=10 \mathrm{~min}$

\begin{tabular}{cc}
\hline Total acoustic power $(\mathrm{W})$ & $\boldsymbol{\Delta \boldsymbol { a } _ { \mathbf { 0 } } ( \mathrm { dB } / \mathrm { cm } )}$ \\
\hline 5 & $1.53 \pm 0.07$ \\
34 & $1.15 \pm 0.11$ \\
37 & $1.44 \pm 0.05$ \\
39 & $1.21 \pm 0.07$ \\
44 & $1.36 \pm 0.03$ \\
49 & $1.62 \pm 0.14$ \\
\hline
\end{tabular}

During slow HIFU treatment, once again significant increases in values of $\beta$ and $\alpha_{0}$ were observed in the lesion created in ex vivo porcine muscle tissues. However, due to the significantly lower HIFU intensity and the special degassing process, the increases in $\Delta \beta$ and $\Delta \alpha_{0}$ and their consequent fluctuations (Figures 15 and 22) can no longer be attributed to bubble activities.

Previous studies have shown that temperature rise affects tissue attenuation coefficient and tissue absorption at temperatures above $50^{\circ} \mathrm{C}$ [24]. Based on the temperature data (Figure 11) at $6 \mathrm{~min}$ after the beginning of HIFU treatment, temperature at the HIFU treatment site was $50^{\circ} \mathrm{C}$. However, despite the fact that temperature levels were below $50^{\circ} \mathrm{C}$, as Figures 13, 15, 20, and 22 revealed, there were significant increases in values of $\beta$ and $\alpha_{0}$ at the ROI from 0 to $6 \mathrm{~min}$ after treatment. Therefore, the temperature rise at the site of HIFU treatment could not have contributed to the increases in $\Delta \beta$ and $\Delta \alpha_{0}$ values.

After HIFU treatment, the high-intensity regions in $\Delta \beta$ and $\Delta \alpha_{0}$ images began to decrease in size and intensity at a relatively slow rate, until they became stable at around 9 min after the end of treatment. This decrease in size and intensity may be attributed to the decrease in temperature at the site of the HIFU exposure to levels below $50^{\circ} \mathrm{C}$ at 2 min after the end of treatment (Figure 11).

In the absence of bubble activities and variations in tissue attenuation coefficient as a function of temperature, it could be concluded that what was being measured by the attenuation slope and attenuation intercept algorithms were changes in acoustic properties of the tissue that were induced due to tissue thermal damage alone. Once again, the high-intensity regions detected in $\Delta \beta$ and $\Delta \alpha_{0}$ images at $9 \mathrm{~min}$ after the end of treatment were used as true 


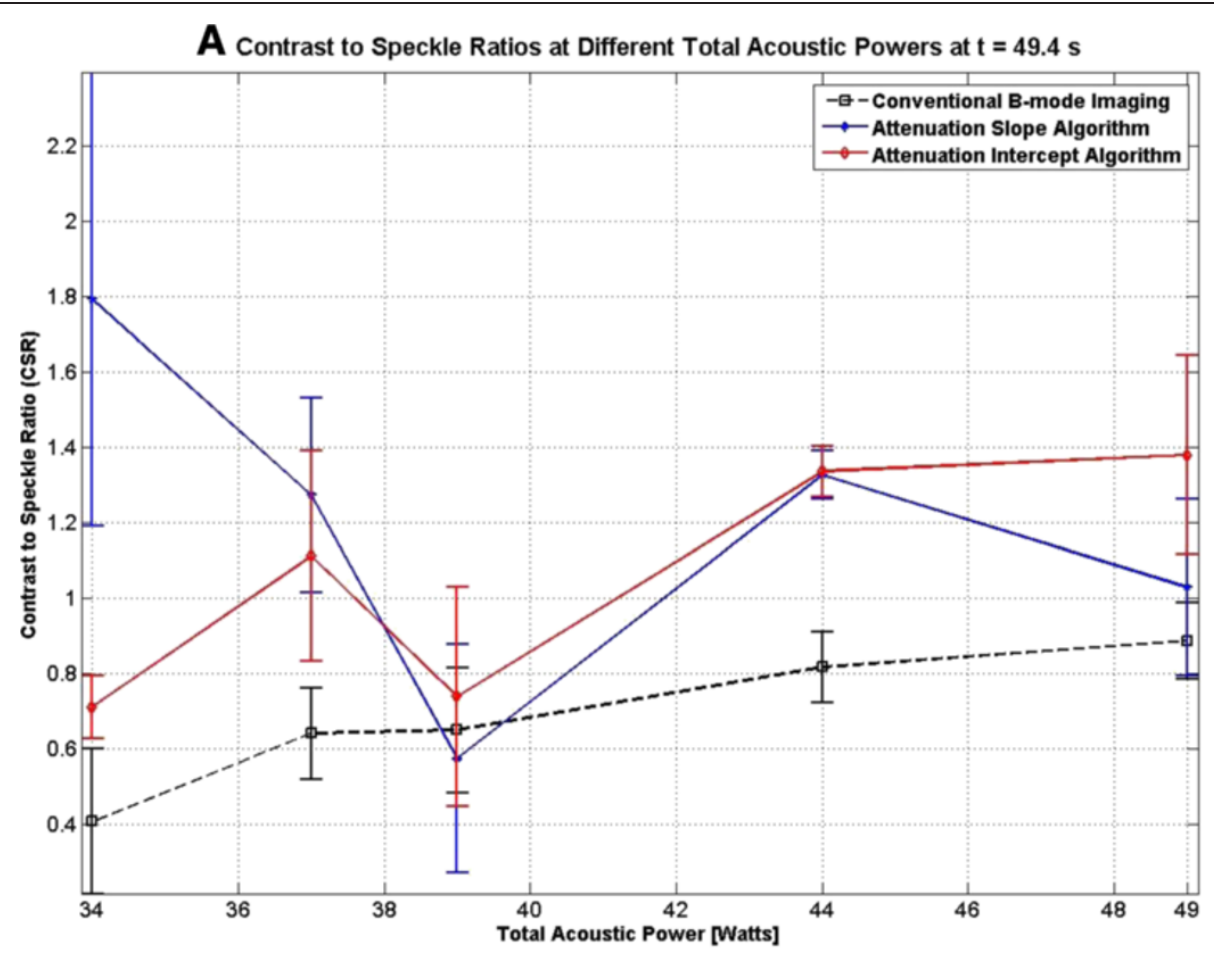

B Contrast to Speckle Ratios at Different Total Acoustic Powers at $\mathrm{t}=10 \mathrm{~min}$

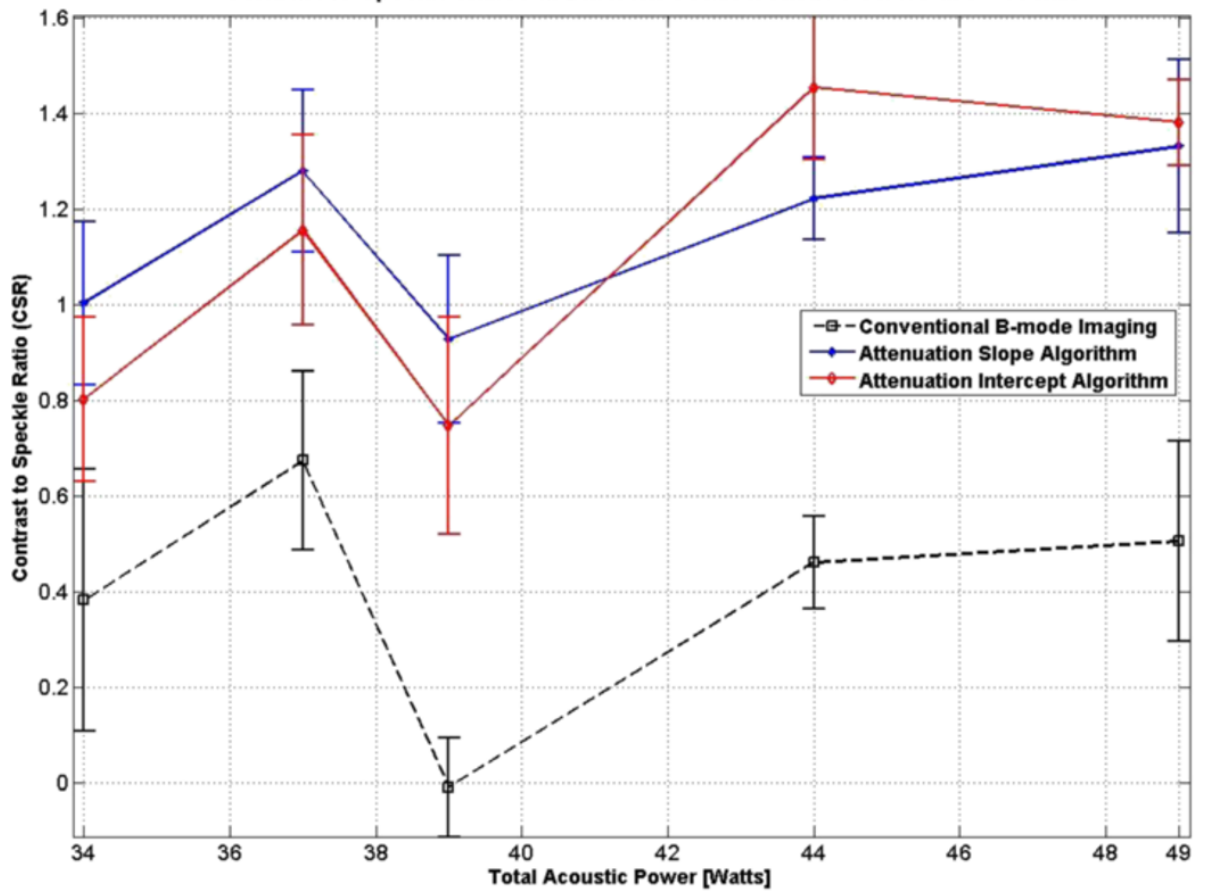

Figure 23 Comparison of contrast-to-speckle ratios. CSR values were calculated at various TAP values at (A) $10 \mathrm{~s}$ and at (B) $10 \mathrm{~min}$ after the end of HIFU treatment.

representations of the boundaries of the coagulated regions of the tissue.

Based on the contrast-to-speckle ratios (Figure 23 and Table 4), there is not enough evidence to suggest that there is a significant difference between the performances of the two algorithms. In comparison to conventional B-mode imaging, in the absence of bubbles and temperature elevations $(10 \mathrm{~min}$ after the HIFU 
Table 4 Contrast-to-speckle ratios at TAP of 5 W and exposure duration of $9 \mathrm{~min}$ and $39 \mathrm{~s}$

\begin{tabular}{lcc}
\hline $\begin{array}{c}\text { Mode of generating } \\
\text { image }\end{array}$ & $\begin{array}{c}\text { CSR at } 10 \mathrm{~s} \text { after the } \\
\text { end of treatment }\end{array}$ & $\begin{array}{c}\text { CSR at } 10 \text { min after } \\
\text { the end of treatment }\end{array}$ \\
\hline $\begin{array}{l}\text { Attenuation slope } \\
\text { algorithm }(\Delta \beta \text { image })\end{array}$ & 0.65 & 0.49 \\
$\begin{array}{l}\text { Attenuation intercept } \\
\text { algorithm }\left(\Delta a_{0}\right)\end{array}$ & 0.81 & 0.48 \\
$\begin{array}{l}\text { Conventional B-mode } \\
\text { imaging }\end{array}$ & 0.47 & 0.21 \\
\hline
\end{tabular}

treatment), the attenuation algorithms significantly outperformed the conventional B-mode images. It was initially expected that, in the presence of bubble activities and temperature elevations, conventional B-mode images would outperform the attenuation algorithms. However, CSR values obtained within $10 \mathrm{~s}(t=49.4 \mathrm{~s})$ after HIFU treatment showed no significant differences between conventional B-mode imaging and $\Delta \beta$ and $\Delta \alpha_{0}$ maps even in the presence of bubble activities and temperature elevations.

The spatial extent of the detected changes in tissue attenuation coefficient parameters were quantitatively compared with the spatial extent of the resulting thermal lesions by plotting the sizes of the detected lesions (at 10 min after the end of treatment) against the measured sizes of the resulting regions of thermal damage (Figure 24). Based on the results shown in Figure 24, the dimension of the lesions detected by both algorithms correlated with the measured sizes of the actual thermal lesions induced within the tissue samples.

In this study, to minimize motion variances and artifacts, the tissue samples were mounted on an acrylic tissue holder with an acoustic window to minimize tissue movements. Furthermore, while investigating the dynamic changes of $\Delta \beta$ and $\Delta \alpha_{0}$, the values were spatially averaged in the region of interest to minimize the effects of any variances. However, slight tissue movements due to the acoustic radiation force, especially at higher powers during

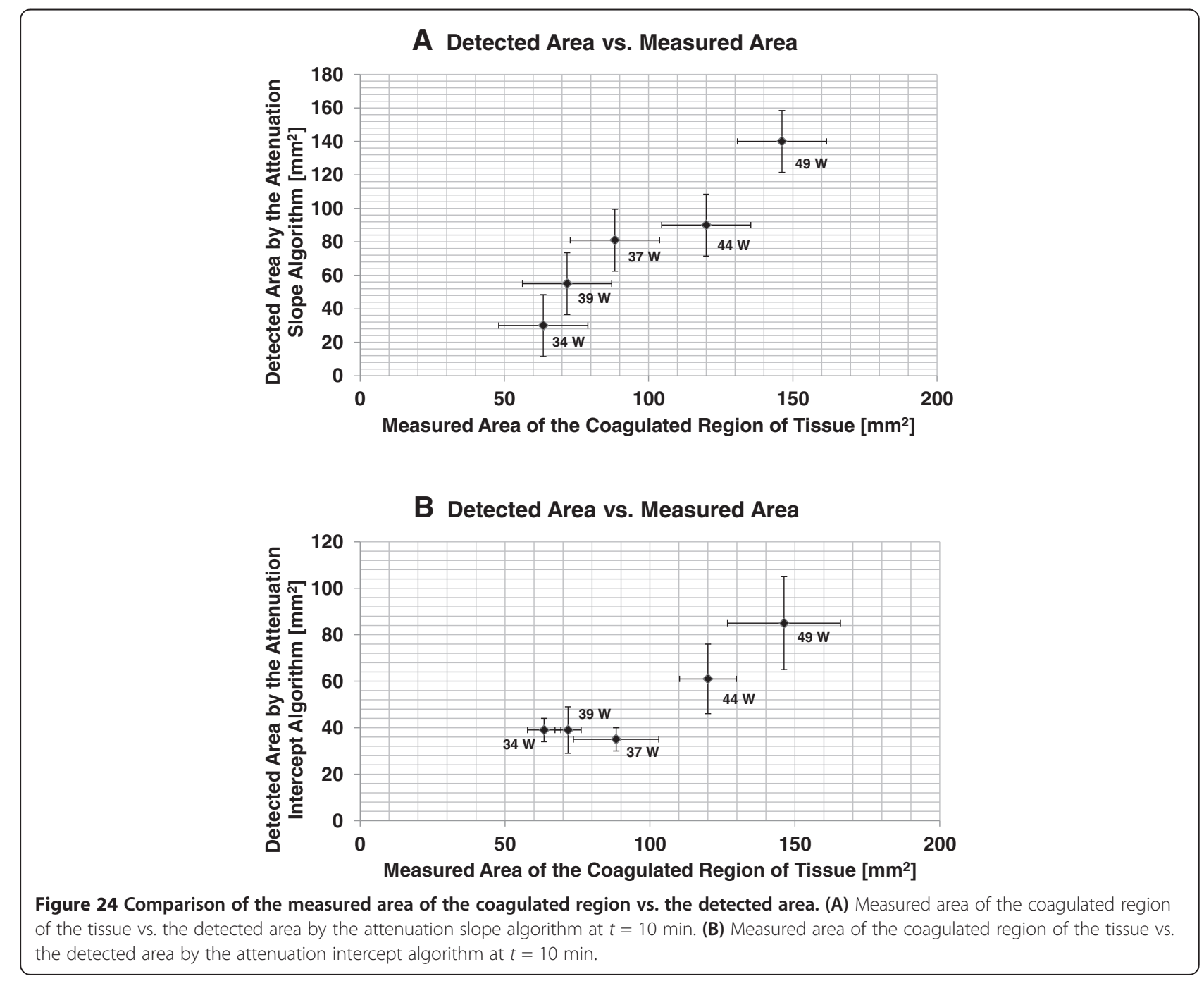


HIFU exposure, were always present to some extent, resulting in movements of the RF data acquisition plane and inducing variances and artifacts in differential $\Delta \beta$ and $\Delta \alpha_{0}$ images. As Figure $4 \mathrm{~A}$ revealed, starting at $11 \mathrm{~s}$ after the beginning of treatment, the HIFU radiation force began to push the tissue at the water tissue boundary along $z=60 \mathrm{~mm}$. This effect became more obvious in the rest of the snapshots at $21.3 \mathrm{~s}, 49.4 \mathrm{~s}, 10 \mathrm{~min}$, and $13 \mathrm{~h}$. This tissue movement induced artifacts in the $\Delta \beta$ images. These artifacts can be seen in the form of voids in the $\Delta \beta$ images at the corresponding times (Figure 5).

\section{Conclusions}

We have obtained preliminary data for the changes in attenuation coefficients induced in ex vivo porcine muscle tissues due to HIFU coagulation. Changes in least squares attenuation coefficient slope $(\Delta \beta)$ and attenuation coefficient intercept $\left(\Delta \alpha_{0}\right)$ were both shown to potentially be reliable indicators of tissue thermal damage caused by HIFU exposure. Based on a simplified model, $\Delta \beta$ and $\Delta \alpha_{0}$ values for any given location were estimated as functions of time and location, with respect to pretreatment values of $\beta$ and $\alpha_{0}$ at the same location, before, during, and after HIFU treatment at different total acoustic powers, using pulseecho ultrasound RF data. The rapid increases in attenuation slope and intercept were generally accompanied by some fluctuations due to rapid rises in tissue temperature and the bubble activities in the HIFU focal region. Violent bubble activities were evident as hyperechoic regions in the B-mode images at the HIFU treatment sites. The performance of B-mode images relied more on the effects of bubble activities compared to the $\Delta \beta$ and $\Delta \alpha_{0}$ images. The dynamic changes of attenuation coefficient parameters ( $\Delta \beta$ and $\Delta \alpha_{0}$ ) may be employed in the development of real-time monitoring and guidance of HIFU therapies and evaluation of HIFU-induced lesions.

At this point, further studies are necessary to determine the relative contributions of bubble activities and thermal tissue damage to the dynamic changes in attenuation coefficient parameters $\left(\Delta \beta\right.$ and $\left.\Delta \alpha_{0}\right)$ in HIFU-induced lesions. To this end, a cavitation detection apparatus could be added to the current experimental setup. Such a system will provide accurate quantitative information on bubble activities (changes in subharmonic and broadband noise), leading to more accurate investigations of dynamic changes of attenuation coefficients during HIFU treatment. Finally, instead of relying on the set of simplifying assumptions, further investigations need to be carried out to study the possibility of expanding the material transfer function so that it will include the effects of changes in scattering properties of tissue.

\section{Abbreviations}

CSR: Contrast-to-speckle ratio; FWHM: Full width at half maximum; HIFU: High-intensity focused ultrasound; MIRF: Material impulse response function; MRI: Magnetic resonance imaging; MTF: Material transfer function; RF: Radio frequency; ROI: Region of interest; TAP: Total acoustic power.

\section{Competing interests}

Both authors declare that they have no competing interests.

\section{Authors' contributions}

SR and JT had equal contributions in conceiving of and designing the research work, carrying out the experiments, analyzing the results, and writing the manuscript. Both authors read and approved the final manuscript.

\section{Acknowledgements}

This work was partially supported by the Ontario Research Fund-Research Excellence (ORF-RE Grant) and the Natural Sciences and Engineering Research Council of Canada (NSERC Discovery Grant) that were awarded to Jahan Tavakkoli. Technical support by Arthur Worthington from the Department of Physics, Ryerson University, in developing the experimental setup is acknowledged.

Received: 20 November 2012 Accepted: 8 July 2013

Published: 2 September 2013

\section{References}

1. Vaezy S, Andrew M, Kaczkowski P, Crum L. Image-guided acoustic therapy. Annu Rev Biomed Eng. 2001; 3:375-90.

2. ter Haar G. Biological effects of ultrasound in clinical applications. In: Ultrasound: Its Chemical, Physical, and Biological Effects. New York: VCH; 1988: p. 305-20.

3. ter Haar GR. Ultrasound focal beam surgery. Ultrasound Med Biol. 1995; 21:1089-100.

4. Ter Haar GR, Robertson D. Tissue destruction with focused ultrasound in vivo. Eur Urol. 1993; 23 Suppl 1:8-11.

5. Fry WJ, Fry FJ. Fundamental neurological research and human neurosurgery using intense ultrasound. IRE Trans Med Electron. 1960; ME-7:166-81.

6. Jolesz FA, Hynynen K. MRI-Guided Focused Ultrasound Surgery. New York: Informa Healthcare; 2007.

7. Tavakkoli J, Sanghvi NT. Ultrasound-guided HIFU and thermal ablation. In: Frenkel V, editor. Therapeutic Ultrasound, Mechanisms to Applications. New York: Nova Science; 2011: p. 137-61.

8. Vaezy S, Shi X, Martin RW, Chi E, Nelson PI, Bailey MR, Crum LA. Real-time visualization of high-intensity focused ultrasound treatment using ultrasound imaging. Ultrasound Med Biol. 2001; 27:33-42.

9. Arefiev A, Prat F, Chapelon JY, Tavakkoli J, Cathignol D. Ultrasound-induced tissue ablation: studies on isolated perfused porcine liver. Ultrasound Med Biol. 1998; 24:1033-43.

10. Seo J, Tran BC, Hall TL, Fowlkes JB, O'Donnell M, Cain CA. Evaluation of ultrasound tissue damage based on changes in image echogenicity. Proc IEEE Ultrason Symp. 2002; 2:1431-4.

11. Zheng X, Vaezy S. An acoustic backscatter-based method for localization of lesions induced by high-intensity focused ultrasound. Ultrasound Med Biol. 2010; 36(4):610-22.

12. Hynynen $\mathrm{K}$. The threshold for thermally significant cavitation in dog's thigh muscle in vivo. Ultrasound Med Biol. 1991; 17:157-69.

13. Shi X, Martin RW, Rouseff D, Vaezy S, Crum LA. Detection of high-intensity focused ultrasound liver lesions using dynamic elastometry. Ultrason Imaging. 1999; 21:107-26.

14. Parker KJ, Huang SR, Musulin RA, Lerner RM. Tissue response to mechanical vibrations for sonoelasticity imaging. Ultrasound Med Biol. 1990; 16:241-6.

15. Righetti R, Kallel F, Stafford RJ, Price RE, Krouskop TA, Hazle JD, Ophir J. Elastographic characterization of HIFU-induced lesions in canine livers. Ultrasound Med Biol. 1999; 25:1099-113.

16. Fahey $B J$, Nightingale $K R$, Stutz DL, Trahey GE. Acoustic radiation force impulse imaging of thermally- and chemically induced lesions in soft tissues: preliminary ex vivo results. Ultrasound Med Biol. 2004; 30:321-8.

17. Souchon R, Rouviere O, Gelet A, Detti V, Srinivasan S, Ophir J, Chapelon JY. Visualization of HIFU lesions using elastography of the human prostate in vivo: preliminary results. Ultrasound Med Biol. 2003; 29:1007-15. 
18. Anand A, Savery D, Hall C. Three-dimensional spatial and temporal temperature imaging in gel phantoms using backscattered ultrasound. IEEE Trans Ultrasound Ferroelectr Frea Control. 2007; 54:23-31.

19. Arthur RM, Straube WL, Starman JD, Moros EG. Noninvasive temperature estimation based on the energy of backscattered ultrasound. Med Phys. 2003; 30:1021-9.

20. Simon C, VanBaren P, Ebbini ES. Two-dimensional temperature estimation using diagnostic ultrasound. IEEE Trans Ultrason Ferroelectr Frea Control. 1998; 45:1088-99.

21. Seip R, Ebbini ES. Noninvasive estimation of tissue temperature response to heating fields using diagnostic ultrasound. IEEE Trans Biomed Eng. 1995; 42:828-39.

22. Bamber JC, Hil CR. Ultrasonic attenuation and propagation speed in mammalian tissues as a function of temperature. Ultrasound Med Biol. 1979; 5:149-57.

23. Bloch S, Michael R, Crum LA, Kaczkowski PJ, Keilman GW, Mourad PD. Measurements of sound speed in excised tissue over temperatures expected under high-intensity focused ultrasound conditions. J Acoust Soc Am. 1998; 103:2868.

24. Damianou CA, Sanghvi NT, Fry FJ, Maass-Moreno R. Dependence of ultrasonic attenuation and absorption in dog soft tissue on temperature and thermal dose. J Acoust Soc Am. 1997; 102:628-34.

25. Miller NR, Bamber JC, Meany PM. Fundamental limitations of noninvasive temperature imaging by means of ultrasound echo strain estimation. Ultrasound Med Biol. 2002; 28:1319-33.

26. Bush NL, Rivens I, ter Haar GR, Bamber JC. Acoustic properties of lesions generated with an ultrasound therapy system. Ultrasound Med Biol. 1993; 9:789-801.

27. Gertner MR, Wilson BC, Sherar MD. Ultrasound properties of liver tissue during heating. Ultrasound Med Biol. 1997; 9:1395-403.

28. Goss SA, Frizzell LA, Dunn F. Ultrasonic absorption and attenuation in mammalian tissues. Ultrasound Med Biol. 1979; 5:181-6.

29. Ophir J, Shawker T, Makland NF, Miller JG. Attenuation estimation in reflection: progress and prospects. Ultrason Imaging. 1984; 6:349-95.

30. Ribault M, Chapelon JY, Cathignol D, Gelet A. Differential attenuation imaging for the characterization of high intensity focused ultrasound lesions. Ultrasound Imaging. 1998; 20:160-77.

31. Bevan PD, Sherar MD. B-scan ultrasound imaging of thermal coagulation in bovine liver: log envelope slope attenuation mapping. Ultrasound Med Biol. 2001; 27:379-87.

32. Bevan PD, Sherar MD. B-scan ultrasound imaging of thermal coagulation in bovine liver: frequency shift attenuation mapping. Ultrasound Med Biol. 2001; 27:809-17.

33. Seip R, Tavakkoli J, Carlson RF, Wunderlich A, Sanghvi NT, Dines KA, Gardner TA. High-intensity focused ultrasound (HIFU) multiple lesion imaging: comparison of detection algorithms for real-time treatment control. In: IEEE Ultrasonics Symposium. Munich: Institute of Electrical and Electronics Engineers; 2002: p. 1395-8.

34. Zhang S, Wan M, Zhong H, Xu C, Liao Z, Liu H, Wang S. Dynamic changes of integrated backscatter, attenuation coefficient and bubble activities during high-intensity focused ultrasound treatment. Ultrasound Med Biol. 2009; 35(11):1828-44.

35. Butt F, Abhari A, Tavakkoli J. An application of high performance computing to improve linear acoustics simulation. In: Spring Simulation Multi-Conference (SpringSim 11). Boston: The Society for Modeling and Simulation International; 2011: p. 71-8.

36. Hill CR, Rivens I, Vaughan MG, ter Haar GR. Lesion development in focused ultrasound surgery: a general model. Ultrasound Med Biol. 1994; 20:259-69.

37. Szabo T. Attenuation. In: Szabo T, editor. Diagnostic Ultrasound Imaging: Inside Out. London: Elsevier; 2004: p. 72-90.

38. Cobbold RS. Attenuation, absorption, scattering, and dispersion. In: Cobbold RS, editor. Foundations of Biomedical Ultrasound. New York: Oxford University Press; 2007: p. 69-73.

39. Coussios CC, Farny CH, ter Haar G, Roy RA. Role of acoustic cavitation in the delivery and monitoring of cancer treatment by high-intensity focused ultrasound (HIFU). Int I Hyperthermia. 2007; 23(2):105-20.
40. Khokhlova VA, Bailey MR, Reed JA, Cunitz BW, Kaczkowski PJ, Crum LA. Effects of nonlinear propagation, cavitation, and boiling in lesion formation by high intensity focused ultrasound in a gel phantom. $J$ Acoust Soc Am. 2006; 119:1834-48.

41. Cobbold RS. Ultrasound imaging systems: design, properties, and applications. In: Cobbold RS, editor. Foundations of Biomedical Ultrasound. New York: Oxford University Press; 2007: p. 515-21.

42. Bailey MR, Couret LN, Sapozhnikov OA, Khokhlova VA, ter Haar GR, Vaezy S, Shi XG, Martin RW, Crum LA. Use of overpressure to assess the role of bubbles in focused ultrasound lesion shape in vitro. Ultrasound Med Biol. 2001; 27:695-708.

doi:10.1186/2050-5736-1-14

Cite this article as: Rahimian and Tavakkoli: Estimating dynamic changes of tissue attenuation coefficient during high-intensity focused ultrasound treatment. Journal of Therapeutic Ultrasound 2013 1:14.

\section{Submit your next manuscript to BioMed Central and take full advantage of:}

- Convenient online submission

- Thorough peer review

- No space constraints or color figure charges

- Immediate publication on acceptance

- Inclusion in PubMed, CAS, Scopus and Google Scholar

- Research which is freely available for redistribution

Submit your manuscript at www.biomedcentral.com/submit
( BioMed Central 